\title{
Vehicle/Guideway Interaction in Maglev Systems
}

by

Y. Cai and S. S. Chen

Materials anả Components Technology Division

D. M. Rote

Center for Transportation Research

March 1992

Work supported by

U.S. DEFARTMENT OF ENERGY

Office of Transportation Technologies 


\section{Contents}

Nomenclature

vii

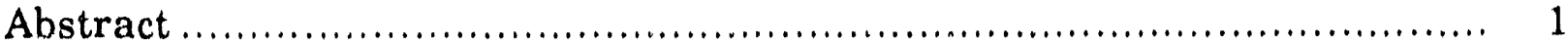

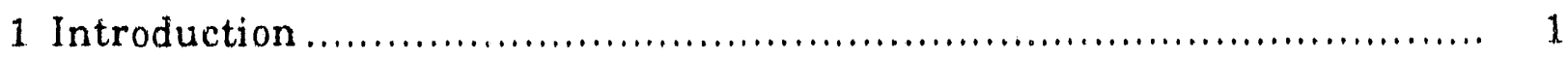

2 The Vehicle as a Moving Force on a Guideway ............................... 2

2.1 A Moving Force on a Single-Span Beam .................................. 3

2.2 A Moving Force on a Two-Span Beam .................................... 5

3 A Two-Degree-of-Freedom Vehicle on a Flexible Guideway .................. 13

3.1 Equations of Motion ................................................... 13

3.2 Results of a Single-Span Guideway .................................... 20

3.3 Re $s$ ults of a Double-Span Guideway ..................................... 24

3.4 Effects of Guideway Surface Irregularities ............................... 32

4 Vehicle/Guideway Interaction in Transrapid Maglev System................. 34

4.1 System Parameter Values .................................................. 37

4.2 Evaluation of Transrapid System.......................................... 39

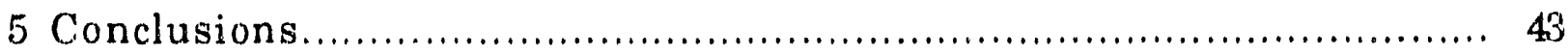

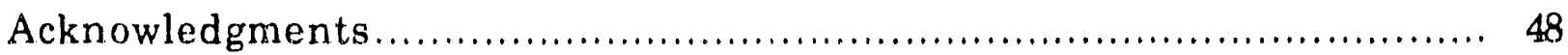

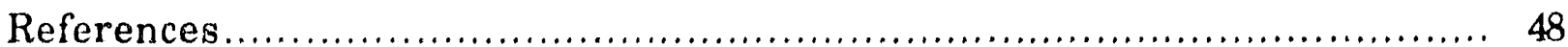




\section{Figures}

1 A simply supported beam subjected to a moving force p.................. 3

2 (a) Maximun displacement ratio $u_{\max }$ and (b) location of force occurrence $\xi_{\mathrm{v}}$ as a function of speed ratio for a single-span beam...... 6

3 Displacement ratio as a function of location of moving force at various values of $\mathrm{v} / \mathrm{v}_{\mathrm{c}}$ for a single-span beam ......................... 7

4 Displacement ratio at midspan as a function of location of moving force with different values of $\Omega / \omega_{1}$ and $\zeta_{n}=2 \%, p_{1} / p_{0}=0.1$ for a

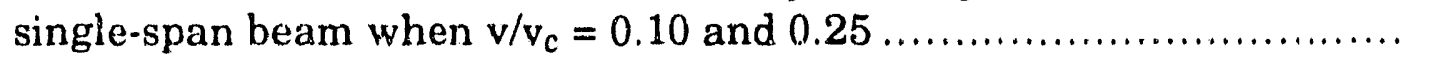

5 A two-span beam subjected to a moving force $p$

6 (a) Maximum displacement ratio $u_{\max }$ at midspan and (b) location of force occurrence $\xi_{v}$, as a function of velocity ratio for single- and

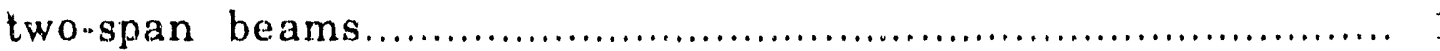

7 Displacement ratio as a function of location of moving force for various values of $\mathrm{v} / \mathrm{v}_{\mathrm{c}}$ for a two-span beam when $\mathrm{x} / \mathrm{L}=0.5$ and $1.5 \ldots \ldots$

8 A two-degree-of-freedom vehicle traveling on a simply supported guideway

9 Time histories of steady-state guideway displacement ratio and vehicle acceleration with speed ratio $\mathrm{v} / \mathrm{v}_{\mathrm{c}}=0.25$ and system parameters $\varepsilon=0.5, \gamma_{m}=0.1, \Omega=3, \gamma_{\mathrm{f}}=0.25, \zeta_{\mathrm{n}}=2 \%, \zeta_{\mathrm{p}}=10 \%$, $\zeta_{s}=25 \%$

10 Time histories of steady-state guideway displacement ratio and vehicle acceleration with speed ratio $\mathrm{v} / \mathrm{v}_{\mathrm{c}}=0.5$ and system pararneters $\varepsilon=0.5, \gamma_{\mathrm{m}}=0.1, \Omega=3, \gamma_{\mathrm{f}}=0.25, \zeta_{\mathrm{n}}=2 \%, \zeta_{\mathrm{p}}=10 \%$, $\zeta_{s}=25 \%$

11 Influence of mass ratio of vehicle to guideway on maximum guideway displacement and vehicle acceleration ratios with system parameters $\gamma_{m}=0.1, \Omega=3, \gamma_{f}=0.25, \zeta_{n}=2 \%, \zeta_{p}=10 \%, \zeta_{s}=25 \% \ldots \ldots$. 
12 Influence of mass ratio of primary to secondary suspensions on maximum guideway displacement and vehicle acceleration ratios with system parameters $\varepsilon=0.5, \Omega=3, \gamma_{\mathrm{f}}=0.25, \zeta_{\mathrm{n}}=2 \%, \zeta_{\mathrm{p}}=10 \%$, $\zeta_{\mathrm{s}}=25 \%$

13 Influence of vehicle/guideway frequency ratio on maximum guideway displacement and vehicle acceleration ratios with system parameters $\varepsilon=0.5, \Omega=3, \gamma_{m}=0.1, \gamma_{f}=0.25, \zeta_{n}=2 \%, \zeta_{p}=10 \%$, $\zeta_{\mathrm{s}}=25 \%$

14 Influence of frequency ratio of secondary to primary suspension on maximum guideway displacement and vehicle acceleration ratios with system parameters $\varepsilon=0.5, \Omega=3, \gamma_{m}=0.1, \zeta_{n}=2 \%$, $\zeta_{p}=10 \%, \zeta_{s}=25 \%$

15 Influence of damping ratio of primary suspension on maximum guideway displacement and vehicle acceleration ratios with system parameters $\varepsilon=0.5, \gamma_{m}=0.1, \Omega=3, \gamma_{f}=0.25, \zeta_{n}=2 \%, \zeta_{s}=25 \% \ldots \ldots \ldots$

16 Influence of damping ratio of secondary suspension on maximum guideway displacement and vehicle acceleration ratios with system parameters $\varepsilon=0.5, \gamma_{m}=0.1, \Omega=3, \gamma_{f}=0.25, \zeta_{n}=2 \%, \zeta_{p}=10 \% \ldots \ldots \ldots$

17. Influence of mass ratio of vehicle/guideway on maximum guideway displacement and vehicle acceleration ratios on a doublespan beam with system parameters $\gamma_{\mathrm{m}}=0.1, \Omega=3, \gamma_{\mathrm{f}}=0.25$, $\zeta_{\mathrm{n}}=2 \%, \zeta_{\mathrm{p}}=10 \%, \zeta_{\mathrm{s}}=25 \%$.

18 Comparison of single-span and double-span beams on maximum guideway displacement and vehicle acceleration ratios with system parameters $\varepsilon=0.5, \gamma_{m}=0.1, \Omega=3, \gamma_{f}=0.25, \zeta_{n}=2 \%, \zeta_{p}=10 \%$, $\zeta_{\mathrm{s}}=25 \%$.

19 Effect of surface irregularity depth ratio of guideway on maximum vehicle accelerations with system parameters $\varepsilon=0.5, \gamma_{\mathrm{m}}=0.1, \Omega=1$, $\gamma_{f}=0.25, \zeta_{n}=2 \%, \zeta_{p}=10 \%, \zeta_{s}=25 \%$ and coefficient $\mathrm{k}=10$

20) Effect of surface i, regularity length of guideway on maximum vehicle accelerations with system parameters $\varepsilon=0.5, \gamma_{\mathrm{m}}=0.1, \Omega=1$, $\gamma_{\mathrm{f}}=0.25, \zeta_{\mathrm{n}}=2 \%, \zeta_{\mathrm{p}}=10 \%, \zeta_{\mathrm{s}}=25 \%$ and surface irregularity depth ratio $r_{d}=0.05$

21 Sketch of Transrapid maglev system 
22 Maximum guideway displacement and vehicle accelerations of Transrapid on a single-span concrete beam versus speed ratio

23 Maximum guideway displacement and vehicle accelerations of Transrapid on a double-span steel beam versus speed ratio

24 Time histories of steady-state guideway displacement and vehicle acceleration of Transrapid with speed $v=400 \mathrm{~km} / \mathrm{h}$ on a single-span concrete beam

25 Time histories of steady-state guideway displacement and vehicle acceleration of Transrapid with speed $v=400 \mathrm{~km} / \mathrm{h}$ on a double-span steel beam

\section{Tables}

1 Beam data for Emsland guideway

2 TR06 vehicle data

3 TR06 suspension system data 


\title{
Nomenclature
}

\author{
C System damping matrix \\ C Viscous damping coefficient of beam \\ $\mathrm{C}_{\mathrm{p}} \quad$ Viscous damping coefficient for primary suspension of vehicle \\ $\mathrm{C}_{\mathrm{S}} \quad$ Viscous damping coefficient for secondary suspension of vehicle \\ d Surface irregularity depth of guideway \\ EI Bending rigidity of guideway structure \\ F Force applied on beam by vehicle \\ f Time-varying force \\ $\mathrm{f}_{\mathrm{n}} \quad$ Natural frequencies of $\mathrm{n}$-th mode \\ $f_{1} \quad$ Natural frequency of fundamental mode \\ g Gravitational acceleration \\ K System stiffness matrix \\ k $\quad$ Coefficient defined in Eq. 45 \\ $k_{n} \quad$ Eigenvalues of $n$-th mode for single-span beam vibration \\ $k_{p} \quad$ Stiffness of primary suspension of vehicle \\ $k_{s} \quad$ Stiffness of secondary suspension of vehicle \\ L Span length of beam \\ $\ell_{0} \quad$ Surface irregularity length of guideway \\ M System mass matrix \\ m Beam mass per unit length \\ $m_{p} \quad$ Mass for primary suspension of vehicle \\ $\mathrm{m}_{\mathrm{s}} \quad$ Mass for secondary suspension of vehicle
}


$\mathrm{p} \quad$ Moving force (consisting of a steady component $\mathrm{p}_{0}$ and a pulsating component $\mathrm{p}_{1} \sin \Omega \mathrm{t}$ )

p System response vector

Q System force vector

$\mathrm{q}_{\mathrm{n}} \quad$ Beam normal coordinates of $\mathrm{n}$-th mode

$r_{d} \quad$ Surface irregularity depth ratio of guideway

$r_{\ell} \quad$ Surface irregularity length ratio of guideway

t Time

$\mathrm{u} \quad$ Displacement ratio of beam $\left(=\mathrm{w}(\mathrm{x}, \mathrm{t}) /\left(\mathrm{p}_{\mathrm{o}} \mathrm{L}^{3 / 48}\right)\right)$

v Vehicle velocity

$\mathrm{v}_{\mathrm{c}} \quad$ Critical vehicle velocity

$v_{n} \quad$ Critical vehicle velocities of $n$-th mode

$v_{\mathrm{r}} \quad$ Velocity ratio

w Total displacement of beam

$\mathrm{x} \quad$ Axial coordinate of beam

Y Dimensionless displacement of beam

y Displacement of beam

$y_{m} \quad$ Midspan displacement of beam

$\mathrm{Y}_{0} \quad$ Dimensionless roughness of beam without loading

$y_{0} \quad$ Roughness of beam without loading

$Y_{p} \quad$ Dimensionless displacement of primary suspension of vehicle

$y_{p} \quad$ Displacement of primary suspension of vehicle

$\mathrm{Y}_{\mathrm{S}} \quad$ Dimensionless displacement of secondary suspension of vehicle

$y_{s} \quad$ Displacement of secondary suspension of vehicle 
$\alpha_{n} \quad$ Dimensionless beam normal coordinates of $n$-th mode

$\gamma_{f} \quad$ Frequency ratio of secondary to primary suspension

$\gamma_{\mathrm{m}} \quad$ Mass ratio of primary to secondary suspension

$\Delta \quad$ Function defined in Eq. 36

$\delta \quad$ Function defined in Eq. 22

$\zeta_{\mathrm{n}} \quad$ Modal damping ratios of $\mathrm{n}$-th mode for beam

$\zeta_{\mathrm{p}} \quad$ Modal damping ratio for primary suspension of vehicle

$\zeta_{\mathrm{s}} \quad$ Modal damping ratio for secondary suspension of vehicle

$\varepsilon$ Mass ratio of vehicle to guideway

$\varepsilon_{\mathrm{p}} \quad$ Mass ratio of vehicle primary suspension to guideway

$\varepsilon_{\mathrm{s}} \quad$ Mass ratio of vehicle secondary suspension to guideway

$\lambda_{n} \quad$ Beam eigenvalues of $n$-th mode

$\xi \quad$ Dimensionless axial coordinate

$\xi_{\mathrm{v}} \quad$ Location of moving force on beam when maximum beam displacement occurs $(=v t / L)$, Location of vehicle on beam when maximum beam displacement occurs $\left(=\mathrm{v}_{\mathrm{r}} \tau / \pi\right)$

$\tau \quad$ Dimensionless time

$\phi_{n}, \varphi_{n} \quad$ Orthonormal function of $n$-th mode

$\Omega \quad$ Oscillating frequency of a moving force on beam, Frequency ratio of vehicle to guideway

$\omega \quad$ Crossing frequency

$\omega_{n} \quad$ Normal frequencies of $n$-th mode

$\omega_{\mathrm{p}} \quad$ Uncoupling natural frequency of primary suspension

$\omega_{\mathrm{s}} \quad$ Uncoupling natural frequency of secondary suspension 


\section{Subscripts}

n

n-th mode

$\mathrm{p}$

Primary suspension

$\mathbf{s}$

Secondary suspension

1

Fundamental mode 


\title{
Vehicle/Guideway Interaction in Maglev Systems
}

\author{
by \\ Y. Cai, S. S. Chen, and D. M. Rote
}

\section{Abstract}

Dynamic interactions between the vehicle and guideway in a high-speed ground transportation system based on magnetically levitated (maglev) vehicles were studied, with an emphasis on the effects of vehicle and guideway parameters. Two dynamic models for the vehicle are presented. In one model, the vehicle is considered to be a moving force traveling at various speeds on a simply supported single- or two-span beam. In the second model, the vehicle is considered to be one-dimensional and has two degrees of freedom; this model consists of the primary and secondary suspensions of the vehicle, with lumped masses, linear springs, and dampings. The Bernoulli-Euler beam equation is used to model the characteristics of a flexible guideway, and the guideway synthesis is based on modal analysis. Analyses were performed to gain an understanding of response characteristics under various loading conditions and to provide benchmark data for verification of existing comprehensive computer programs and some basic design guidelines for maglev systems. Finally, the German Transrapid maglev system was evaluated.

\section{Introduction}

A high-speed ground transportation system based on magnetically levitated (maglev) vehicles propelled by a linear electric motor has been proposed to meet future intercity transportation requirements. One possible and attractive approach is in replacing air travel for selected intercity trips of 100 to 600 miles. The maglev system will offer the advantages of lower noise and emissions and better ride quality, as well as potential energy savings and economic benefits (Bohn and Steinmetz 1985; Johnson et al. 1989; Katz et al. 1974; Zicha 1986).

For several decades, research and development has been performed in the areas of magnetic levitation, response of maglev vehicles to rough guideways, interaction of variously suspended vehicles with flexible guideways, and optimization of vehicle suspensions. The results of that research and development are useful in providing appropriate criteria for the design of maglev systems (Bohn and Steinmetz 1985; Chiu et al. 1971; Iguchi and Hara 1985; Katz et al. 1974; Sinha 1987). More emphasis should be placed on guideway design, because the 
cost of the guideway structure is expected to be $\approx 60-80 \%$ of the initial capital (Uher 1989; Zicha 1986). Thus, guideway design is a critical area of potential capital savings. An optimized design for guideways will be important for a high-speed maglev system with good ride quality. As vehicle speeds of maglev systems increase to $200-300 \mathrm{mi} / \mathrm{hr}$, or as guideways become lighter and more flexible to reduce costs, the dynamic interactions between vehicles and guideways become an important problem and will play a dominant role in establishing vehicle suspension requirements and specifications for guideway stiffness, weight, and span length (Chiu et al. 1971; Zicha 1986).

The purpose of this paper is to discuss the problems associated with modeling vehicle/guideway interactions and to explain the response characteristics of maglev systems under various loading conditions. This study will provide some benchmark data for verification of existing comprehensive computer programs and some basic design guidelines for maglev systems. Of particular interest are the effects of variations in fundamental vehicle and guideway parameters that relate to their dynamic interaction. Simplified models have been analyzed to provide basic information; they are intended to answer questions such as (a) Under what conditions can we neglect the dynamic coupling of vehicles and guideways for EDS and EMS systems? and (b) What models of the vehicles and guideways should be used in analyzing different maglev systems?

This study used two dynamic models for vehicles. In the first model, the vehicle is considered to be a moving force traveling at various speeds on a simply supported single- or two-span beam; in the second, the vehicle is considered a onedimensional model with two degrees of freedom; the model consists of the primary and secondary suspensions of a vehicle, with lumped masses, linear springs, and dampings. These simplified vehicle models, in which only the vertical motion of the vehicle is considered, are based on the assumption that vertical motion is dominant and other motions can be ignored when the vertical motion is evaluated. For a flexible guideway, the elastic deformation of the guideway must be considered. Therefore, the Bernoulli-Euler beam equation is used to model the guideway characteristiss. In the above cases, guideway synthesis is based on a modal analysis method; both closed-form and numerical solutions are applied to solve the equations of motion for vehicle/guideway interaction. The results show that a numerical solution with time integration has the same accuracy as the closed-form solution.

\section{The Vehicle as a Moving Force on a Guideway}

When the coupling of vehicle and guideway is ignored, a vehicle may be described as a moving force traveling on a flexible guideway. Two guideways are 
considered: single-span beam and two-span beam. Reports of extensive studies of moving loads acting on elastic structures have been published (Fryba 1972; Kerr 1981; Ting et al. 1974; Wilson 1973). This study emphasizes applications to maglev systems.

\subsection{A Moving Force on a Single-Span Beam}

In Fig. 1, a simply supported single-span beam is subjected to a force moving with speed $\mathrm{v}$. The equation of motion for this case is given by

$$
\mathrm{EI} \frac{\partial^{4} w}{\partial x^{4}}+C \frac{\partial w}{\partial t}+\ln \frac{\partial^{2} w}{\partial t^{2}}=p \delta(x-v t)
$$

where $w$ is the beam deflection, $x$ is the axial coordinate of the beam, $t$ is time, $m$ is the beam mass per unit length, $\mathrm{EI}$ is the flexural rigidity, $\mathrm{C}$ is the viscous damping coefficient, and the moving force $\mathrm{p}$ consists of a steady component $\mathrm{p}_{0}$ and a pulsating component $p_{1} \sin \Omega t$. The boundary conditions are

$$
\mathrm{w}(0, \mathrm{t})=0, \quad \mathrm{w}(\mathrm{L}, \mathrm{t})=0, \quad \frac{\partial^{2} \mathrm{w}}{\partial \mathrm{x}^{2}}(0, \mathrm{t})=0, \quad \frac{\partial^{2} \mathrm{w}(\mathrm{L}, \mathrm{t})}{\partial \mathrm{x}^{2}}=0,
$$

and the initial conditions are

$$
w(x, 0)=0, \quad \frac{\partial w}{\partial t}(x, 0)=0 .
$$

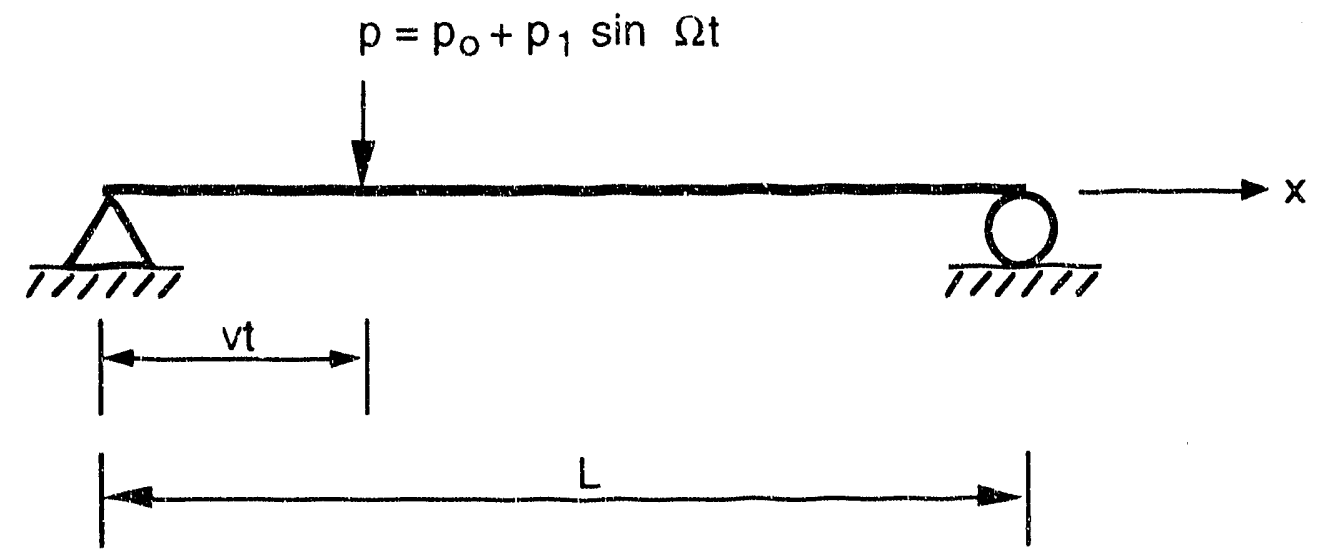

Fig. 1. A simply supported beam subjected to a moving force $p$ 
The mathematical problem specifie 1 by Eqs. $1-3$ can easily be solved with a modal analysis method. The results are surnmarized as follows:

$$
w(x, t)=\sum_{n=1}^{\infty} q_{n}(t) \phi_{n}(x)
$$

where $\phi_{n}$, the orthonormal function of the $n-t h$ mode, is defined by the equation

$$
\phi_{\mathrm{n}}(\mathrm{x})=\sqrt{2} L \sin \left(\frac{\mathrm{nrx}}{\mathrm{L}}\right)
$$

where $q_{n}$ represents the be:m normal coordinates of the $n$-th mode, and $q_{n}(t)$ is the solution of the following equation:

$$
\begin{aligned}
& \frac{d^{2} q_{n}}{d t^{2}}+2 r_{n} \omega_{n} \frac{d q_{n}}{d t}+\omega_{n}^{2} q_{n}=\frac{\sqrt{2}}{L^{2} m}\left(p_{0}+p_{1} \sin \Omega t\right) \sin (n \omega t), \\
& \omega_{n}=\frac{n^{2} \pi^{2}}{L^{2}} \sqrt{\frac{E I}{m}}, \quad \zeta_{n}=\frac{C}{2 m \omega_{n}}, \quad \omega=\frac{\pi v}{L} .
\end{aligned}
$$

Note that $\omega_{n}$ is the natural frequency (in radians) of the $n$-th mode, $\zeta_{\mathrm{n}}$ is the corresponding modal damping ratio, $\omega$ is the crossing frequency (in radians), and $\Omega$ is tue oscillating frequency of a moving force on the bearn.

From Eq. 6, several interesting features are noted.

When $\omega_{n}=n \omega$,

$$
v_{n}=\frac{n \pi}{L} \sqrt{\frac{E I}{m}} \quad \text { or } \quad v_{n}=\frac{2 f_{n} L}{n} \text {, and } f_{n}=\frac{\omega_{n}}{2 \pi}
$$

where $v_{n}$ is the critical speed of the $n$-th mode, and $f_{n}$ represents the natural frequencies of the a-th mode. The first critical speed is $v_{c}$ $\left(=(\pi / \mathrm{L})(\sqrt{\mathrm{E} L / \mathrm{m}})=2 r_{1} \mathrm{~L}\right)$. When $\mathrm{v}=\mathrm{v}_{c}$, the critical vehicle velocity of the fundamental mode, the crossing frequency $\left(v_{c} / L\right)$ is equal to twice the natural frequency of the fundamental mode $f_{1}$.

When $\omega_{n}=\Omega \pm n \omega / 2$, the pulsating force is in resonance with the beam.

Beam displacement can be calculated easily from Eqs. 4-6. To make the results easily understood, all beam displacements are expressed as the ratio of the 
bearn displacement to the static deflection at $\mathrm{x}=\mathrm{L} / 2$ due to $\mathrm{p}_{0}$ at $\mathrm{x}=\mathrm{L} / 2$; this deflection is equal to $p_{0} L 3 / 4 B E I$. The dispracement ratio is denotad by $u(x / L)$, which is a function of $v / v_{c}, \zeta_{n}$, and $x / L$.

Equation 4 can be used to calculate the beam displacement at any location and at any time as a function of damping $\zeta_{\mathrm{n}}$ and velocity ratio $\mathrm{v} / \mathrm{v}_{\mathrm{c}}$. The $\max$ imum displacement is of particular interest because it is related to the stresses in the beam and vehicle response. The maximum displacement ratio, $u_{\max }$, for a single-span beam was found to occur at $x / L=0.8$. The maximum displacement ratio $u_{\max }$ and the location of the moving force $\xi_{v}(=v t / L)$ when the maximum displacement develops as a function of velocity ratio $v / v_{c}$ are given in Fig. 2 for a single-span beam. From Fig. 2 , the maximurn displacement ratio is $\approx 1.7$ for $\zeta_{n}=$ $2 \%$ when $\mathrm{v} / \mathrm{v}_{\mathrm{c}}$ is $\approx 0.6$. As damping is increased to $10 \%$, the maximum displacement ratio is reduced to $\approx 1.52$. When the velocity ratio is $>1.5$ for $\zeta_{n}=10 \%$ and 1.75 for $\zeta_{\mathrm{n}}=2 \%$, the displacement ratio is $<1$. For $\mathrm{v} / \mathrm{v}_{\mathrm{c}}<0.5$, maximum displacement develops when the moving force is close to the midspan. As $v / v_{c}$ increases, the location of the moving force $x / L$ increases with $v / v_{c}$.

Because the maximum displacement is at $x / L=0.5$ on a single-span bearn, the time history of the displacement ratio at $\mathrm{x} / \mathrm{L}=0.5$, as a function of the location of the inoving force $p_{0}$, is as shown in Fig. 3 for various values of $v / v_{c}$. In Fig. 3, the location $\xi_{\mathrm{v}}=\mathrm{vt} / \mathrm{L}=0-1$ means the moving force is on the first beam, and $\xi_{\mathrm{v}}=$ $1-2$ means the moving force is on the next beam. For very small values of $v / v_{c}$, the response is very close to the static load $\left(\mathrm{v} / \mathrm{v}_{\mathrm{c}}=0.0\right.$ ); for $0.5<\mathrm{v} / \mathrm{v}_{\mathrm{c}}<1.0$, the maximum response occurs when the load po has already passed the midspan; and for $v / v_{c}>1$, the maximum response occurs after $p_{0}$ has left the beam to go on to the next beam. Increasing damping tends to decrease beam response regardless of the value of $\mathrm{v} / \mathrm{v}_{\mathrm{c}}$. The modal damping ratio is a few percent in practical systems.

Figure 4 shows the displacement ratio at the midspan that is due to a moving force with a steady component $\mathrm{p}_{0}$ and a pulsating component $\mathrm{p}_{1}\left(=0.1 \mathrm{p}_{0}\right)$, for two values of velocity ratio and several frequency ratios $\Omega / \omega_{1}$. When $\Omega=\omega_{1}$, as shown in Fig. 4a, the pulsating component is in resonance with the fundamental natural frequency and its response increases significantly. Once the moving force leaves the span, its response will start to decrease.

\subsection{A Moving Force on a Two-Span Beam}

Figure 5 shows a beam with two equal spans subjected to a moving force 0 . The general solution method is similar to that for a single-span beam. The results are summarized as follows: 

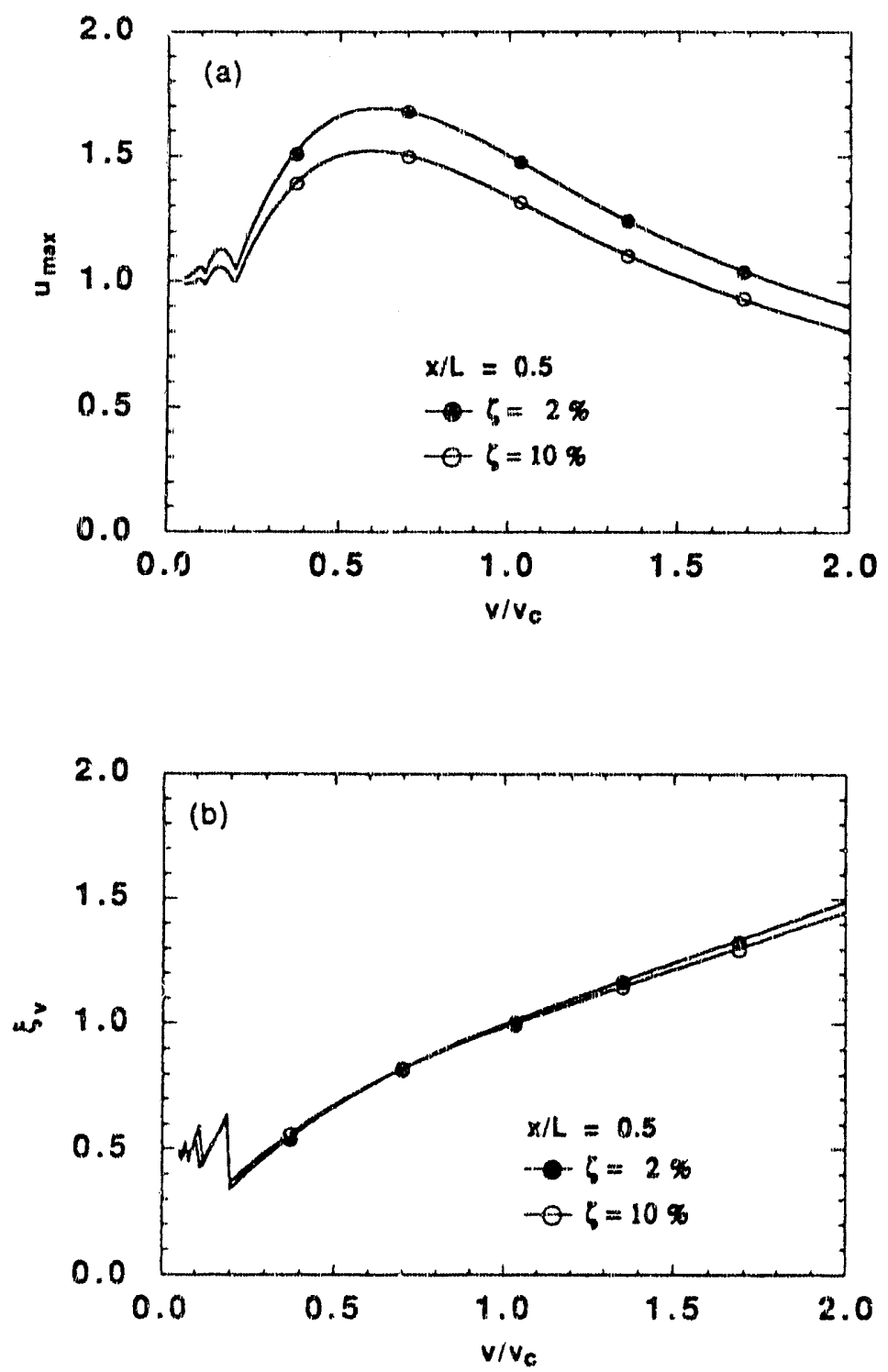

Fig. 2. (a) Maximum displacement ratio $u_{\max }$ and (b) location of forse occurrence $\xi_{v}$ as a function of speed ratio for a single-span beam 


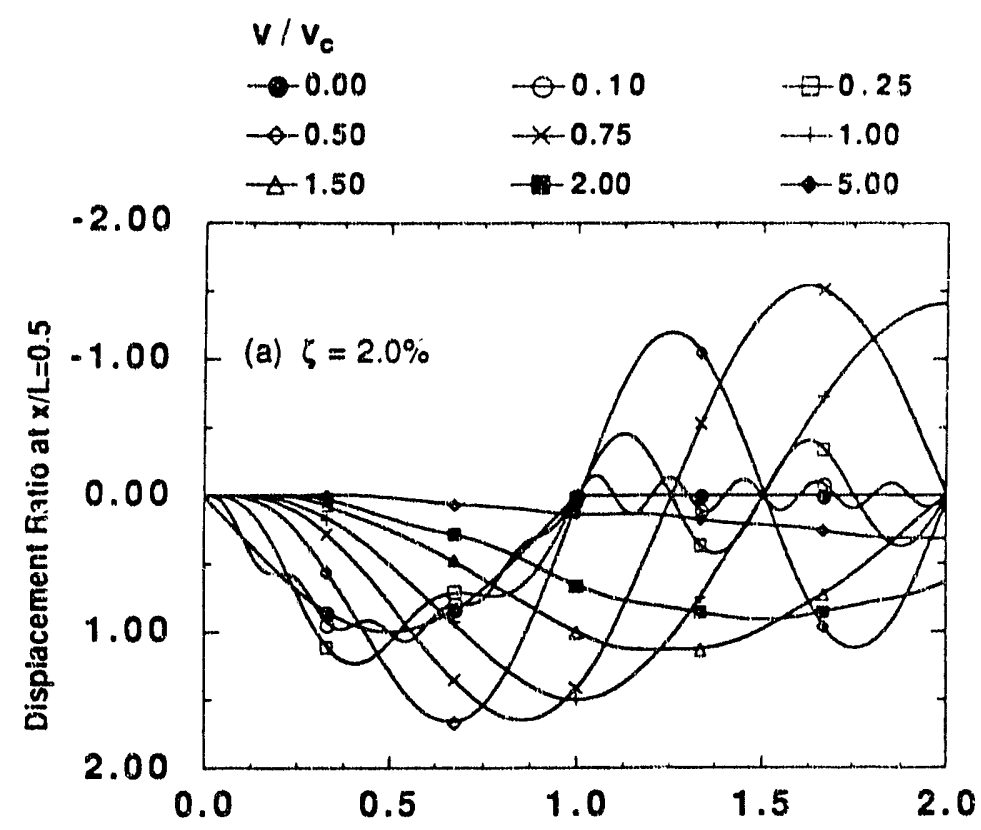

Location of Moving Force $P_{0}, \xi_{v}$

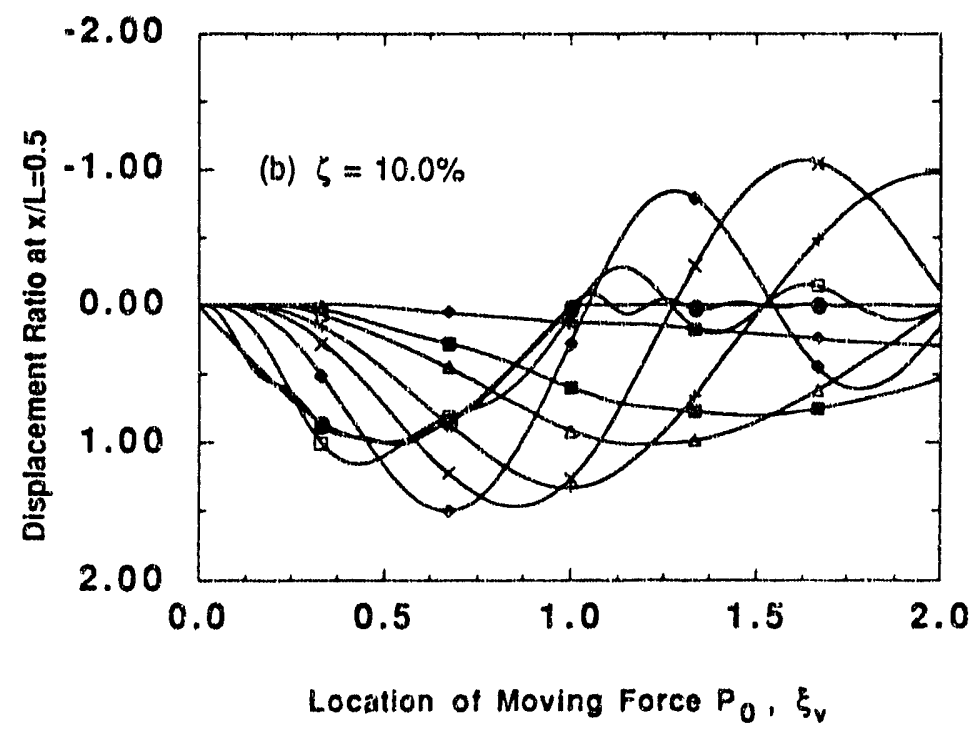

Fig. 3. Displacement ratio as a function of location of moving force at various values of $v / v_{c}$ for a single-span beam 

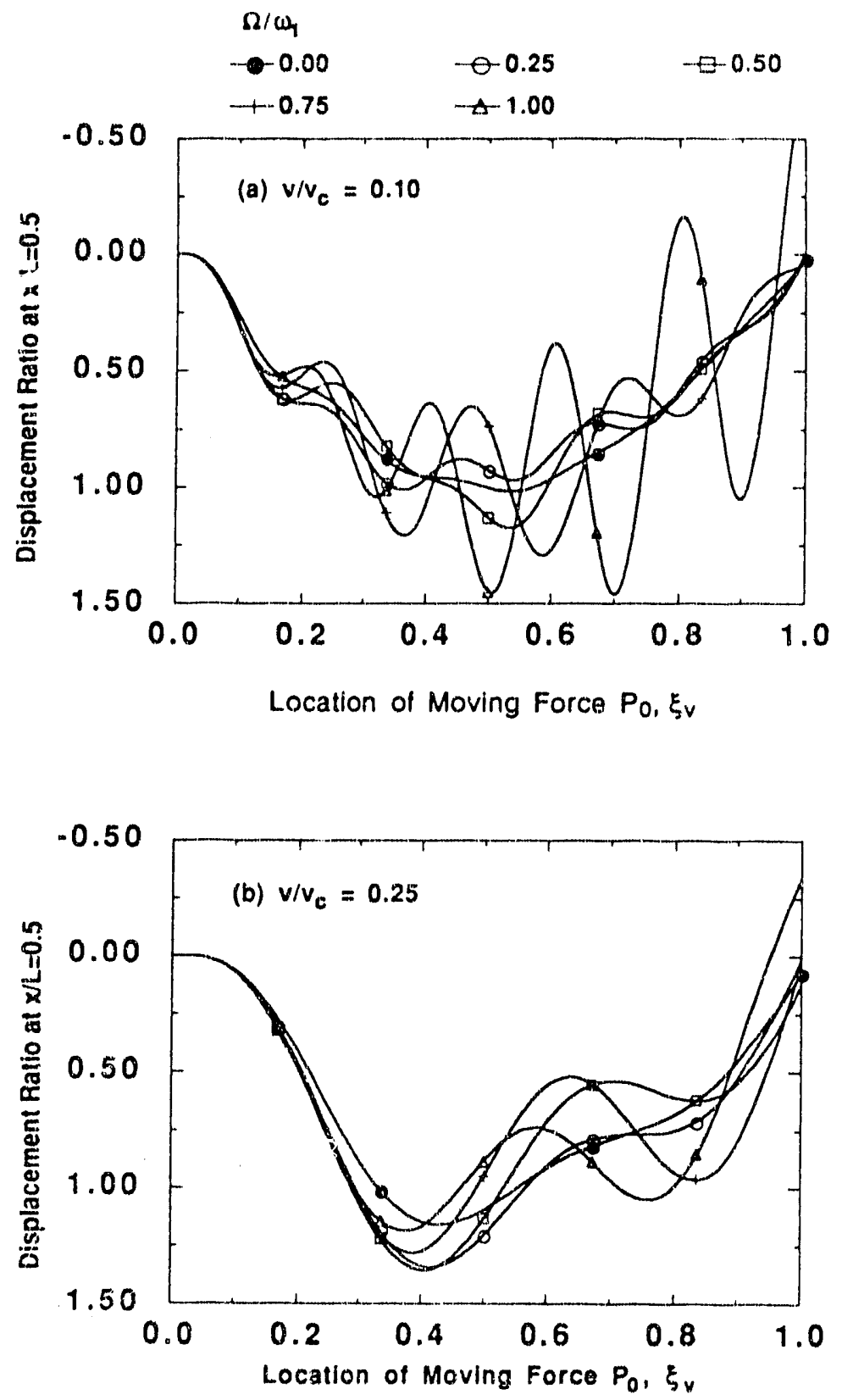

Fig. 4. Displacement ratio at midspan as a function of location of moving force with different values of $\Omega / \omega_{1}$ and $\zeta_{n}=2 \%, p_{1} / p_{o}=0.1$ for a single-span beam when $(a) v / v_{c}=0.10$ and (b) $v / v_{c}=0.25$ 


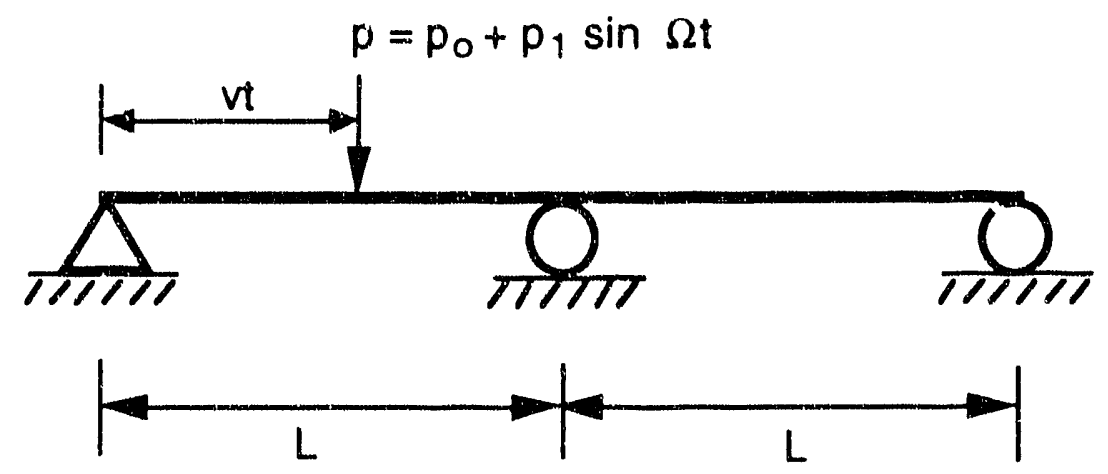

Fig. 5. A two-span beam subjected to a moving force $p$

$$
w(x, t)=\sum_{n=1}^{\infty} q_{n}(t) \phi_{n}(x), \quad x=0-2 L
$$

The mode shapes are given as follows:

(1)

$$
\begin{aligned}
& \mathrm{n}=1,3,5,7,9, \ldots \\
& \phi_{\mathrm{n}}(\mathrm{x})=\sin \left[\frac{(\mathrm{n}+1) \pi}{2} \frac{\mathrm{x}}{\mathrm{L}}\right]
\end{aligned}
$$

(2)

$$
\begin{aligned}
\mathrm{n} & =2,4,6,8,10, \ldots \\
\phi_{\mathrm{n}}(\mathrm{x}) & =\sin \frac{\mathrm{k}_{\mathrm{n}} \mathrm{x}}{\mathrm{L}}-\frac{\sin \mathrm{k}_{\mathrm{n}}}{\sinh \mathrm{k}_{\mathrm{n}}} \sinh \frac{\mathrm{k}_{\mathrm{n}} \mathrm{x}}{\mathrm{L}}, \quad 0 \leq \mathrm{x} \leq \mathrm{L} ; \\
\phi_{\mathrm{n}}(\mathrm{x}) & =\sin \mathrm{k}_{\mathrm{n}}\left(\frac{2 \mathrm{~L}-\mathrm{x}}{\mathrm{L}}\right)-\frac{\sin \mathrm{k}_{\mathrm{n}}}{\sinh \mathrm{k}_{\mathrm{n}}} \sinh \mathrm{k}_{\mathrm{n}}\left(\frac{2 \mathrm{~L}-\mathrm{x}}{\mathrm{L}}\right), \quad \mathrm{L} \leq \mathrm{x} \leq 2 \mathrm{~L} ;
\end{aligned}
$$

where $k_{n}$, eigenvalue of the $n$-th mode for single-span beam vibration, is the solution of the characteristic equation

$$
\tan k_{n}=\tanh k_{n} .
$$

The values of $k_{n}$ obtained from Eq. $11 a_{i}$ e 3.39, 7.07, 10.21, 13.35, ...

$\mathrm{q}_{n}(t)$ is calculated from the following equations 
(1) $\mathrm{n}=1,3,5,7, \ldots$

$$
\frac{d^{2} q_{n}}{d t^{2}}+2 \zeta_{n} \omega_{n} \frac{d q_{n}}{d t}+\omega_{n}^{2} q_{n}=\left(p_{0}+p_{1} \sin \Omega t\right) \sin (n \omega t) ;
$$

(2) $\mathrm{n}=2,4,6,8, \ldots$

a. $0 \leq \mathrm{vt} \leq \mathrm{L}$

$$
\begin{aligned}
\frac{d^{2} q_{n}}{d t^{2}} & +2 \zeta_{n} \omega_{n} \frac{d q_{n}}{d t}+\omega_{n}^{2} q_{n} \\
& =\left(p_{0}+p_{1} \sin \Omega t\right)\left[\sin \left(k_{n} v t\right)-\frac{\sin k_{n}}{\sinh k_{n}} \sinh \left(k_{n} v t\right)\right]
\end{aligned}
$$

b. $\mathrm{L} \leq \mathrm{vt} \leq 2 \mathrm{~L}$

$$
\begin{aligned}
\frac{d^{2} q}{d t^{2}} & +2 \zeta_{n} \omega_{n} \frac{d q_{n}}{d t}+\omega_{n}^{2} q_{n} \\
= & \left(p_{o}+p_{1} \sin \Omega t\right)\left[\sin k_{n}(2-v t)-\frac{\sin k_{n}}{\sinh k_{n}} \sinh k_{n}(2-v t)\right] .
\end{aligned}
$$

The normal frequencies $\omega_{\mathrm{n}}$ in Eqs. 12,13, and 14 are given by

$$
\omega_{\mathrm{n}}=\frac{\lambda_{\mathrm{n}}^{2}}{\mathrm{~L}^{2}} \sqrt{\frac{\mathrm{EI}}{\mathrm{m}}}, \quad \zeta_{\mathrm{n}}=\frac{\mathrm{C}}{2 \mathrm{~m} \omega_{\mathrm{n}}}, \quad \omega=\frac{\pi \mathrm{v}}{\mathrm{L}},
$$

where $\lambda_{n}$, the beam eigenvalues of the $n$-th mode, are defined by the equation

$$
\begin{aligned}
\lambda_{\mathrm{n}} & =\frac{(\mathrm{n}+1) \pi}{2}, \quad \mathrm{n}=1,3,5,7, \ldots \\
& =\mathrm{k}_{\mathrm{n}}, \quad \mathrm{n}=2,4,6,8, \ldots
\end{aligned}
$$

For a two-span beam, the maximum displacement ratio, defined the same as for a single-span beam, was found to occur at $\mathrm{x} / \mathrm{L}=0.5$ or 1.5 . The maximum displacement ratio and the location of the moving force when maximum displacement developed in single- and two-span beams are shown in Fig. 6. Figure 7 shows the time history of the displacement ratio at $x / L=0.5$ and 1.5 for various values of $v / v_{c}$ when force $p_{c}$ is at various locations. 

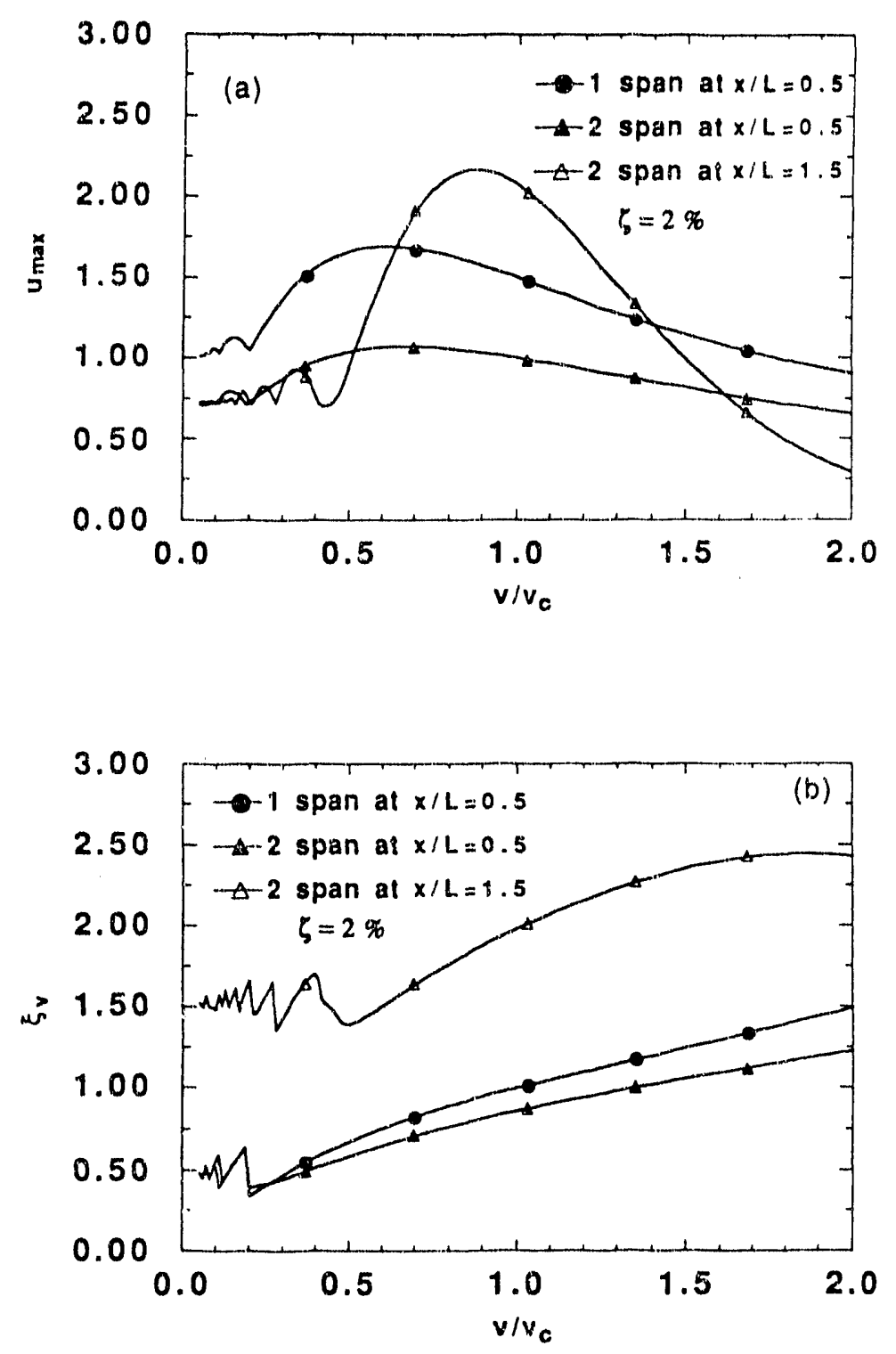

Fig. 6. (a) Maximum displacement ratio $u_{\max }$ at midspan and (b) location of force occurrence $\xi_{v}$, as a function of velocity ratio for single and two. span beams 

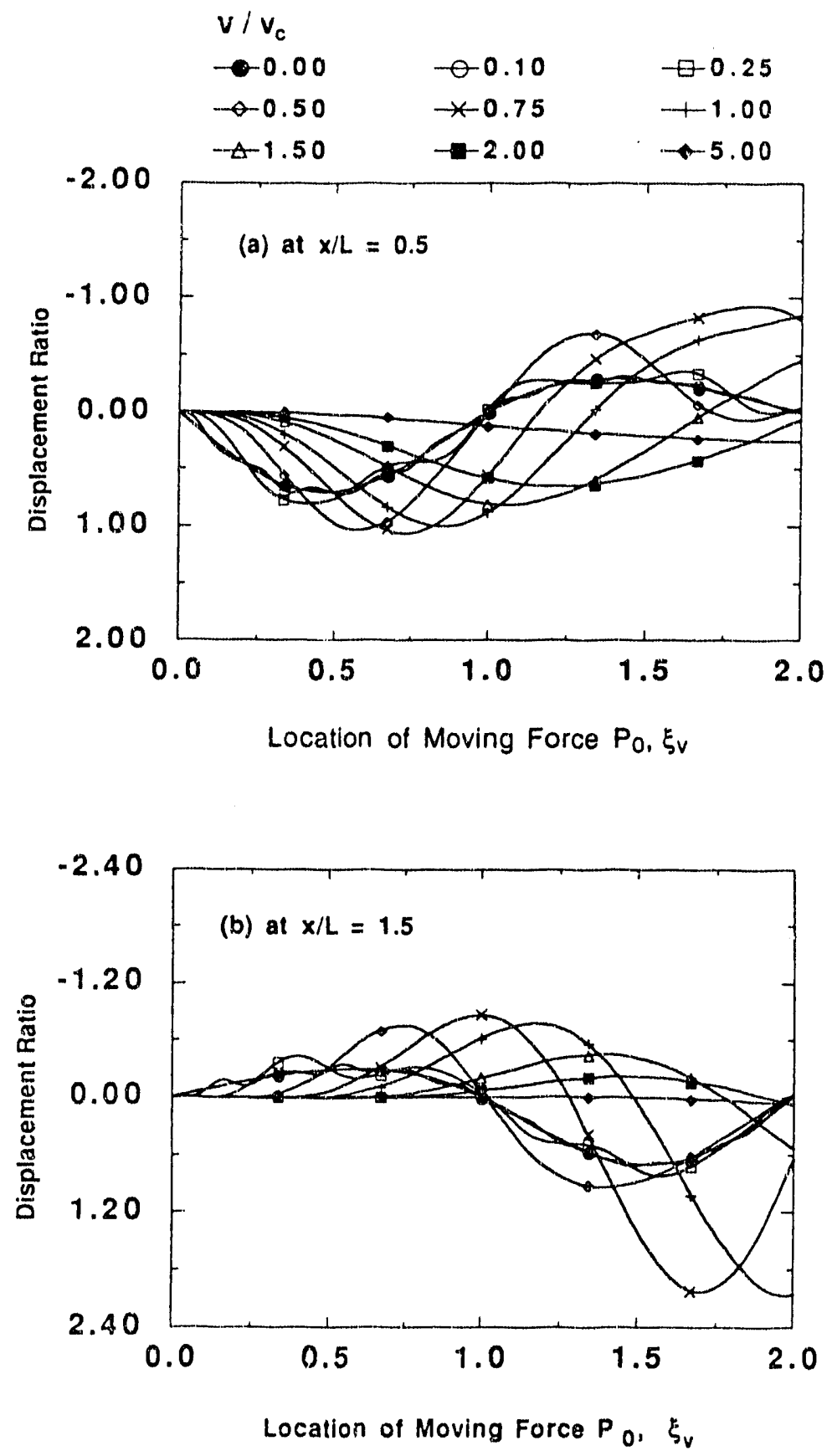

Fig. 7. Displacement ratio as a function of location of moving force for various values of $v / v_{c}$ for a twospan beam when (a) $x / L=0.5$ and (b) $x / L=1.5$ 
The response characteristics at $\mathrm{x} / \mathrm{L}=0.5$ are similar to those of a single-span beam, except that the maximum displacement ratio is smaller. The displacement ratio at $\mathrm{x} / \mathrm{L}=1.5$ changes significantly with $\mathrm{v} / \mathrm{v}_{\mathrm{c}}$. When $\mathrm{v} / \mathrm{v}_{\mathrm{c}}$ is between 0.65 and 1.4, the displacement ratio is larger than that of a single-span beam. When maximum displacement occurs at $\mathrm{x} / \mathrm{L}=1.5$, the location of the moving force is close to $\mathrm{x} / \mathrm{L}=1.5$ when $\mathrm{v} / \mathrm{v}_{\mathrm{c}}$ is smaller than $\approx 0.6$ and then increases with $\mathrm{v} / \mathrm{vic}_{\mathrm{c}}$.

For maglev systems, the velocity ratio, $v / v_{c}$, is expected to be no larger than 0.5 (Sinha 1987). In this situation, the maximum displacement ratio for a twospan beam is smaller than that for a single-span beam. Without consiciering other factors, a two-span beam appears to be more efficient in achieving better ride quality. It is noteworthy that the Transrapid Guideway at Emsland, Germany, uses single-span concrete beams and double-span steel beams (Bohn and Steinmetz 1985).

\section{A Two-Degree-of-Freedom Vehicle on a Flexible Guideway}

\section{1 Equations of Motion}

A one-dimensional vehicle model with two degrees of freedom and traveling on a simply supported guideway is shown in Fig. 8. The vehicle model consists of two lumped masses $m_{p}$ and $m_{s}$, two linear springs $k_{p}$ and $k_{s}$, and two viscous dampings $C_{p}$ and $C_{s}$, representing primary and secondary suspensions, respectively. The guideway is considered to be a Bernoulli-Euler beam of uniform cross section. Displacement $w(x, t)$ of the beam consists of initial irregularities $y_{0}(x)$ and deformation $y(x, t)$, which is caused by the vehicle and measures positively in the downward direction,

$$
w(x, t)=y_{0}(x)+y(x, t) .
$$

The displacement of two masses $m_{p}$ and $m_{s}$ are $y_{p}$ and $y_{s}$, which measure positively upward from their static-equilibrium positions. The equations of motion for the vehicle are then

$$
\begin{aligned}
& m_{p} \frac{d^{2} y_{p}}{d t^{2}}+m_{s} \frac{d^{2} y_{s}}{d t^{2}}+C_{p}\left(\frac{d y_{p}}{d t}+\frac{d w}{d t}\right)+k_{p}\left(y_{p}+w\right)=-\left(m_{p}+m_{s}\right) g \\
& m_{s} \frac{d^{2} y_{s}}{d t^{2}}+C_{s}\left(\frac{d y_{s}}{d t}-\frac{d y_{p}}{d t}\right)+k_{s}\left(y_{s}-y_{p}\right)=-m_{s} g
\end{aligned}
$$




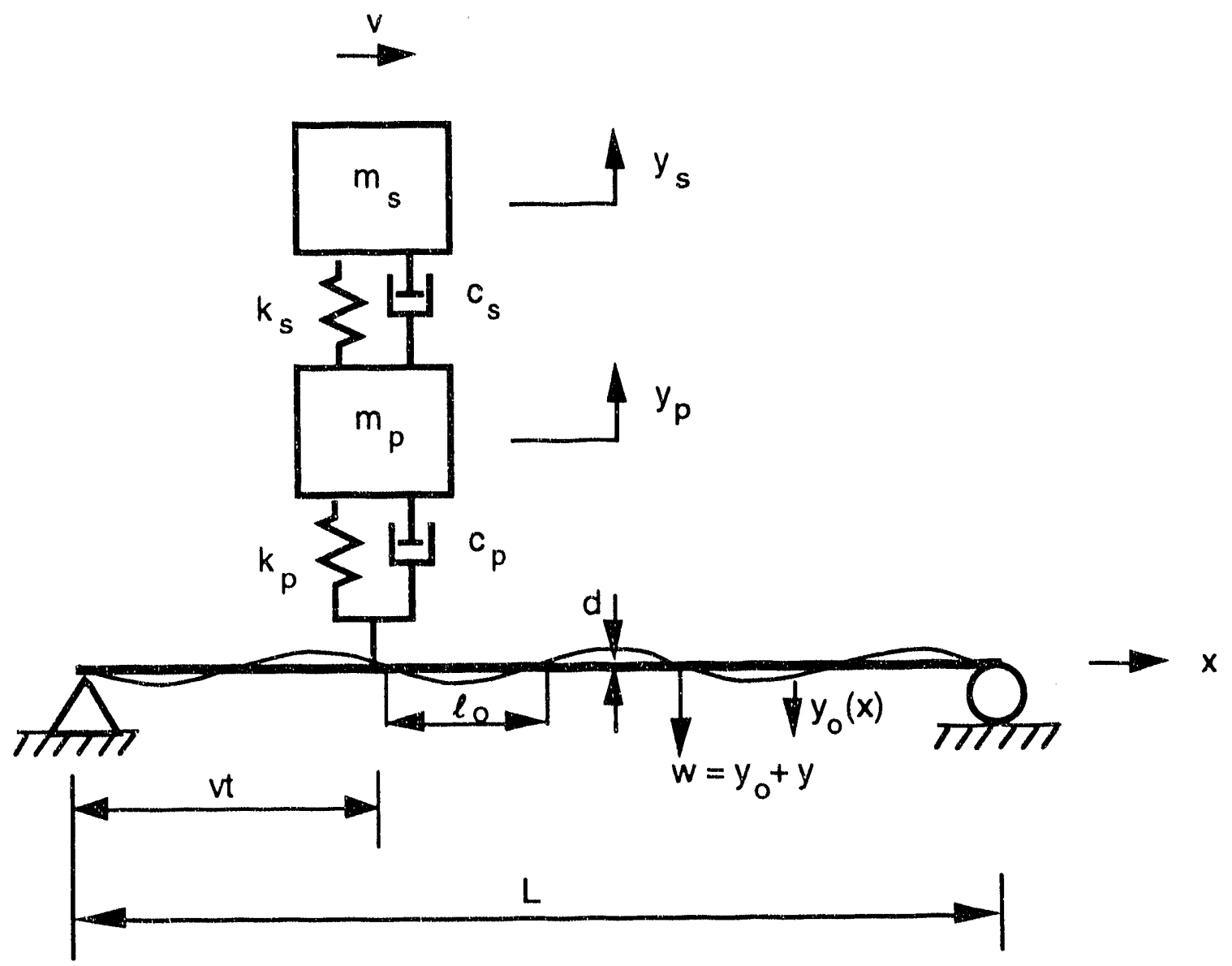

Fig. 8. A two-degree-of-freedom vehicle traveling on a simply supported guideway

where $t$ is time and $g$ is gravitational acceleration. When a vehicle is traveling at a constant velocity $v$, the force $F(x, t)$ applied to the beam by the vehicle may be expressed as

$$
\begin{aligned}
& F(x, t)=f(t) \delta(x-v t) \\
& f(t)=\left(m_{p}+m_{s}\right) g+\left(m_{p} \frac{d^{2} y_{p}}{d t^{2}}+m_{s} \frac{d^{2} y_{s}}{d t^{2}}\right)
\end{aligned}
$$

where

$$
\delta= \begin{cases}1 & 0 \leq \mathrm{x}(=\mathrm{vt}) \leq \mathrm{L} \\ 0 & \mathrm{x}(=\mathrm{vt})>\mathrm{L} .\end{cases}
$$

Then, the equation of motion of the beam is 


$$
\mathrm{EI} \frac{\partial^{4} \mathrm{y}}{\partial \mathrm{x}^{4}}+\mathrm{C} \frac{\partial \mathrm{y}}{\partial \mathrm{t}}+\mathrm{m} \frac{\partial^{2} \mathrm{y}}{\partial \mathrm{t}^{2}}=\mathrm{F}(\mathrm{x}, \mathrm{t})
$$

where $\mathrm{x}$ is the axial coordinate of the beam, EI is the bending rigidity of the beam, $\mathrm{C}$ is the viscous damping coefficient, and $\mathrm{m}$ is the beam mass per unit length. The boundary conditions of the beam are

$$
y(t, 0)=\frac{\partial^{2} y(t, 0)}{\partial x^{2}}=0, \quad y(t, L)=\frac{\partial^{2} y(t, L)}{\partial x^{2}}=0 .
$$

In the modal analysis method, the displacement of the beam is expressed in terms of orthonormal modes $\varphi_{n}(x)$ :

$$
\begin{aligned}
& \varphi_{n}(x)=\sqrt{2} \sin \left(\frac{n \pi x}{L}\right), \\
& y(x, t)=\sum_{n=1}^{\infty} q_{n}(t) \varphi_{n}(x) .
\end{aligned}
$$

$\mathrm{q}_{\mathrm{n}}(\mathrm{t})$ is the solution of the equation

$$
\frac{\mathrm{d}^{2} \mathrm{q}_{\mathrm{n}}}{\mathrm{dt}^{2}}+2 \zeta_{\mathrm{n}} \omega_{\mathrm{n}} \frac{\mathrm{dq_{n }}}{\mathrm{dt}}+\omega_{\mathrm{n}}^{2} q_{\mathrm{n}}=\frac{1}{\mathrm{Lm}} \int_{0}^{L} \mathrm{~F}(\mathrm{x}, \mathrm{t}) \varphi_{\mathrm{n}}(\mathrm{x}) \mathrm{dx},
$$

where $\omega_{n}$ and $\zeta_{n}$, the circular frequency and modal damping ratio of the beam, are given by

$$
\omega_{\mathrm{n}}=\frac{\lambda_{\mathrm{n}}^{2}}{\mathrm{~L}^{2}} \sqrt{\frac{\mathrm{EI}}{\mathrm{m}}}, \quad \zeta_{\mathrm{n}}=\frac{\mathrm{C}}{2 \mathrm{~m} \omega_{\mathrm{n}}} .
$$

For a single-span beam, $\lambda_{n}=2 n \pi, n=1,2,3, \ldots$

When a concentrated load $\left(m_{p}+m_{s}\right) g$ is placed at the midspan, the midspan displacement associated with the fundamental mode can be derived from Eq. 27 to give

$$
\mathrm{q}_{1}=\frac{\sqrt{2}\left(\mathrm{~m}_{\mathrm{p}}+\mathrm{m}_{\mathrm{s}}\right) \mathrm{g}}{\mathrm{mL} \omega \omega_{1}^{2}}
$$


Therefore, the midspan displacement $\mathrm{y}_{\mathrm{m}}$ is

$$
y_{m}=q_{1} \varphi_{1}\left(\frac{L}{2}\right)=\frac{2\left(m_{p}+m_{s}\right) g}{m L \omega_{1}^{2}} .
$$

Uncoupled natural frequencies and modal damping ratios are defined as follows:

$$
\begin{aligned}
& \omega_{p}=\sqrt{\frac{k_{p}}{m_{p}+m_{s}}}, \quad \omega_{s}=\sqrt{\frac{k_{s}}{m_{s}}} \\
& \zeta_{p}=\frac{C_{p}}{2\left(m_{p}+m_{s}\right) \omega_{p}}, \quad \zeta_{s}=\frac{C_{s}}{2 m_{s} \omega_{s}} .
\end{aligned}
$$

Several nondimensional parameters are introduced:

$$
\begin{aligned}
& \varepsilon=\frac{\mathrm{m}_{\mathrm{p}}+\mathrm{m}_{\mathrm{s}}}{\mathrm{mL}}, \quad \varepsilon_{\mathrm{p}}=\frac{\mathrm{m}_{\mathrm{p}}}{\mathrm{mL}}, \quad \varepsilon_{\mathrm{s}}=\frac{\mathrm{m}_{\mathrm{s}}}{\mathrm{mL}}, \\
& \gamma_{\mathrm{m}}=\frac{\mathrm{m}_{\mathrm{p}}}{\mathrm{m}_{\mathrm{s}}}, \quad \Omega=\frac{\omega_{1}}{\omega_{\mathrm{p}}}, \quad \gamma_{\mathrm{f}}=\frac{\omega_{\mathrm{s}}}{\omega_{\mathrm{p}}}, \\
& \mathrm{Y}_{\mathrm{p}}=\frac{\mathrm{J}_{\mathrm{p}}}{\mathrm{y}_{\mathrm{m}}}, \quad \mathrm{Y}_{\mathrm{s}}=\frac{\mathrm{y}_{\mathrm{s}}}{\mathrm{y}_{\mathrm{m}}}, \quad \mathrm{Y}_{\mathrm{o}}=\frac{\mathrm{y}_{0}}{\mathrm{y}_{\mathrm{m}}}, \quad \mathrm{Y}=\frac{\mathrm{y}}{\mathrm{y}_{\mathrm{m}}}, \\
& \xi=\mathrm{x} / \mathrm{L}, \quad \alpha_{\mathrm{n}}=\frac{\mathrm{q}_{\mathrm{n}}}{\mathrm{y}_{\mathrm{m}}}, \quad \tau=\omega_{1} \mathrm{t}, \quad \mathrm{v}_{\mathrm{r}}=\frac{\pi \mathrm{v}}{\mathrm{L} \omega_{1}}=\frac{\mathrm{v}}{\mathrm{v}_{1}}=\frac{\mathrm{v}}{\mathrm{v}_{\mathrm{c}}} \quad\left(\mathrm{v}_{\mathrm{c}}=2 \mathrm{f}_{1} \mathrm{~L}\right), \quad \xi_{\mathrm{v}}=\frac{\mathrm{vt}}{\mathrm{L}}=\frac{\mathrm{v}_{\mathrm{r}} \tau}{\pi} .
\end{aligned}
$$

These parameters are based on published data related to maglev systems (Bohn and Steinmetz 1985; Coffey et al. 1972, 1973, 1974; Johnson et al. 1989; Philco-Ford Corp. 1975; Richardson and Wormley 1974).

$v_{r}$ is the ratio of vehicle speed to critical speed $v_{c}$. The critical speed $v_{c}$ is equal to $2 f_{1} L\left(f_{1}=\omega_{1} / 2 \pi\right)$. $\varepsilon, \varepsilon_{p}$, and $\varepsilon_{s}$ are mass ratios of vehicle components to the guideway. $\gamma_{\mathrm{m}}$ is mass ratio of primary suspension to secondary suspension. 
These ratios vary considerably. In general, $0.1 \leq \varepsilon \leq 2.0$, and $\varepsilon_{\mathbf{s}}$ is much larger than $\varepsilon_{\mathrm{p}} . \gamma_{\mathrm{m}}$ ranges from 0.05 to 0.50 .

$\Omega$ is the ratio of the fundamental frequency of the guideway to the frequency of the primary suspension system of the vehicle; typically, this ratio is between 1 and 10 .

$\gamma_{\mathrm{f}}$ is the ratio of uncoupled frequencies of primary to secondary suspensions and depends on the ratios of $k_{p} / k_{s}$ and $\left(m_{p}+m_{s}\right) / m_{s}$. It ranges from 0.04 to 0.25 .

$\zeta_{\mathrm{p}}, \zeta_{\mathrm{s}}$, and $\zeta_{\mathrm{n}}$ are damping ratios of the vehicle and guideway. The guideway damping ratio $\zeta_{n}$ is generally small; its value is about $1-5 \%$, depending on the span length. In general, it is 1 or $2 \%$ (Sinha 1987). The vehicle damping ratios $\zeta_{p}$ and $\zeta_{\mathrm{s}}$ depend on design. In our study, $\zeta_{\mathrm{p}}$ ranges from 0.05 to 0.5 and $\zeta_{\mathrm{s}}$ ranges from 0.1 to 0.75 .

Using Eqs. 17, 31, and 32, we can rewrite Eqs. 18, 19, and 27 as

$$
\begin{aligned}
& \Omega^{2} \ddot{\mathrm{Y}}_{\mathrm{p}}+\frac{\varepsilon_{\mathrm{s}}}{\varepsilon_{\mathrm{p}}} \Omega^{2} \ddot{\mathrm{Y}}_{\mathrm{s}}+2 \zeta_{\mathrm{p}} \Omega\left(\dot{\mathrm{Y}}_{\mathrm{p}}+\dot{\mathrm{Y}}\right)+\frac{\varepsilon}{\varepsilon_{\mathrm{p}}}\left(\mathrm{Y}_{\mathrm{p}}+\mathrm{Y}\right) \\
& =-\frac{\Omega^{2}}{2 \varepsilon_{\mathrm{p}}}-2 \zeta_{\mathrm{p}} \Omega \dot{\mathrm{Y}}_{\mathrm{o}}\left(\xi_{\mathrm{v}}\right)-\frac{\varepsilon}{\varepsilon_{\mathrm{p}}} \mathrm{Y}_{\mathrm{o}}\left(\xi_{\mathrm{v}}\right) \\
& \Omega^{2} \ddot{\mathrm{Y}}_{\mathrm{s}}+2 \zeta_{\mathrm{s}} \Omega \gamma_{\mathrm{f}}\left(\dot{\mathrm{Y}}_{\mathrm{s}}-\dot{\mathrm{Y}}_{\mathrm{p}}\right)+\gamma_{\mathrm{f}}^{2}\left(\mathrm{Y}_{\mathrm{s}}-\mathrm{Y}_{\mathrm{p}}\right)=-\frac{\Omega^{2}}{2 \varepsilon} \\
& \ddot{\alpha}_{\mathrm{n}}+2 \zeta_{\mathrm{n}} \frac{\omega_{\mathrm{n}}}{\omega_{1}} \dot{\alpha}_{\mathrm{n}}+\left(\frac{\omega_{\mathrm{n}}}{\omega_{1}}\right)^{2} \alpha_{\mathrm{n}}=\Delta\left(\frac{1}{2}+\varepsilon_{\mathrm{p}} \ddot{\mathrm{Y}}_{\mathrm{p}}+\varepsilon_{\mathrm{s}} \ddot{\mathrm{Y}}_{\mathrm{s}}\right) \varphi_{\mathrm{n}}\left(\zeta_{\mathrm{v}}\right),
\end{aligned}
$$

where

$$
\Delta= \begin{cases}1 & 0 \leq \xi_{\mathrm{v}} \leq 1 \\ 0 & \xi_{\mathrm{v}}>1\end{cases}
$$

For a single-span beam,

$$
\begin{aligned}
\varphi_{\mathrm{n}}\left(\xi_{\mathrm{v}}\right) & =\sqrt{2} \sin \left(\mathrm{n} \pi \xi_{\mathrm{v}}\right), \\
& =\sqrt{2} \sin \left(\mathrm{n} \mathrm{v}_{\mathrm{r}} \tau\right),
\end{aligned}
$$


for a two-span beam

$$
\left.\begin{array}{c}
\varphi_{\mathrm{n}}\left(\xi_{\mathrm{v}}\right)=\sin \left[\frac{\left.(\mathrm{n}+1) \pi_{\mathrm{v}}\right]}{2} \xi_{\mathrm{v}}\right] \mathrm{n}=1,3,5,7,9, \ldots \\
\begin{array}{c}
\varphi_{\mathrm{n}}\left(\xi_{\mathrm{v}}\right)=\sin \mathrm{k}_{\mathrm{n}}-\frac{\sin \mathrm{k}_{\mathrm{n}}}{\sinh \mathrm{k}_{\mathrm{n}}} \sinh \mathrm{k}_{\mathrm{n}} \xi_{\mathrm{v}} \\
0 \leq \xi_{\mathrm{v}} \leq 1
\end{array} \\
\varphi_{\mathrm{n}}\left(\xi_{\mathrm{v}}\right)=\sin \mathrm{k}_{\mathrm{n}}\left(2-\xi_{\mathrm{v}}\right)-\frac{\sin \mathrm{k}_{\mathrm{n}}}{\sinh \mathrm{k}_{\mathrm{n}}} \sinh \mathrm{k}_{\mathrm{n}}\left(2-\xi_{\mathrm{v}}\right) \\
1 \leq \xi_{\mathrm{v}} \leq 2
\end{array}\right\} \mathrm{n}=2,4,6,8,10, \ldots
$$

and

$$
Y(\xi, \tau)=\sum_{n=1}^{\infty} \alpha_{n}(\tau) \varphi_{n}(\xi) .
$$

Equations 33 and 35 are coupled second-order ordinary differential equations with constant coefficients. The number of normal coordinates in the beam equation goes to infinity, but significant contributions come from a few natural modes. Let this number be $n$. The system of Eqs. $33-35$ can be represented in matrix form by an $N(=2+n)$-size set (Yadav and Upadhyay 1991):

$$
M \ddot{p}+C \dot{p}+K p=Q
$$

where

$$
\mathbf{M}=\left[\begin{array}{ccccc}
\Omega^{2} & \frac{\varepsilon_{\mathrm{s}}}{\varepsilon_{\mathrm{p}}} \Omega^{2} & 0 & 0 & \ldots \\
0 & \Omega^{2} & 0 & 0 & \ldots \\
-\Delta \varepsilon_{p} \varphi_{1}\left(\xi_{v}\right) & -\Delta \varepsilon_{\mathrm{s}} \varphi_{1}\left(\xi_{v}\right) & 1 & 0 & \ldots \\
-\Delta \varepsilon_{p} \varphi_{2}\left(\xi_{v}\right) & -\Delta \varepsilon_{\mathrm{s}} \varphi_{2}\left(\xi_{v}\right) & 0 & 1 & \ldots \\
\vdots & \vdots & \vdots & \vdots & \vdots
\end{array}\right]
$$


$\mathbf{C}=\left[\begin{array}{ccccc}2 \zeta_{\mathrm{p}} \Omega & 0 & 2 \zeta_{\mathrm{p}} \Omega \varphi_{1}\left(\xi_{\mathrm{v}}\right) & 2 \zeta_{\mathrm{p}} \Omega \varphi_{2}\left(\xi_{\mathrm{v}}\right) & \ldots \\ -2 \zeta_{\mathrm{s}} \Omega \gamma_{\mathrm{f}} & 2 \zeta_{\mathrm{s}} \Omega \gamma_{\mathrm{f}} & 0 & 0 & \ldots \\ 0 & 0 & \omega_{\mathrm{n} n}\left(\frac{\omega_{1}}{\omega_{1}}\right) & 0 & \ldots \\ 0 & 0 & 0 & 2 \zeta_{\mathrm{n}}\left(\frac{\omega_{2}}{\omega_{1}}\right) & \ldots \\ \vdots & \vdots & \vdots & \vdots & \vdots\end{array}\right]$

$\mathbf{K}=\left[\begin{array}{ccccc}\frac{\varepsilon}{\varepsilon_{\mathrm{p}}} & 0 & \frac{\varepsilon}{\varepsilon_{\mathrm{p}}} \varphi_{1}\left(\xi_{\mathrm{v}}\right) & \frac{\varepsilon}{\varepsilon_{\mathrm{p}}} \varphi_{2}\left(\xi_{\mathrm{v}}\right) & \ldots \\ -\gamma_{\mathrm{f}}^{2} & \gamma_{\mathrm{f}}^{2} & 0 & 0 & \ldots \\ 0 & 0 & \left(\frac{\omega_{1}}{\omega_{1}}\right)^{2} & 0 & \ldots \\ 0 & 0 & 0 & \left(\frac{\omega_{2}}{\omega_{1}}\right)^{2} & \ldots \\ \vdots & \vdots & \vdots & \vdots & \vdots\end{array}\right]$

(Cont'd)

$\mathbf{Q}=\left[\begin{array}{c}-\frac{\Omega^{2}}{2 \varepsilon_{\mathrm{p}}}-2 \zeta_{\mathrm{p}} \Omega \dot{Y}_{0}\left(\xi_{\mathrm{v}}\right)-\frac{\varepsilon}{\varepsilon_{\mathrm{p}}} \mathrm{Y}_{\mathrm{o}}\left(\xi_{\mathrm{v}}\right) \\ -\frac{\Omega^{2}}{2 \varepsilon} \\ \frac{\Delta}{2} \varphi_{1}\left(\xi_{\mathrm{v}}\right) \\ \frac{\Delta}{2} \varphi_{2}\left(\xi_{\mathrm{v}}\right) \\ \vdots\end{array}\right], \quad \mathbf{p}=\left[\begin{array}{c}\mathrm{Y}_{\mathrm{p}} \\ \mathrm{Y}_{\mathrm{s}} \\ \alpha_{1} \\ \alpha_{2} \\ \vdots\end{array}\right]$

$\mathbf{M}, \mathbf{C}$ and $\mathbf{K}$ are $\mathbf{N} \times \mathbf{N}$ square matrices and $\mathbf{Q}$ and $\mathbf{p}$ are $\mathbf{N}$ vectors. In this sturiy, different numbers of modes $\mathrm{n}$ have been used to compare the results; $\mathrm{n}=5(\mathrm{~N}=i)$ was used to provide adequate accuracy for vehicle/guideway systems with various traveling speeds. Therefore, Eq. 39 can be solved by a closed-form or numerical solution. 
The inter sst of this study is in the steaảy-state or repetitive condition of guideway deflections and vehicle heave accelerations for one-dimensional vehicles. The steady state exists after a vehicle with a given arbitrary set of initial conditions has traversed a sufficient number of spans in which the state of the vehicle entering a span is identical to its state when leaving the span or, in fact, entering the next span. For a vehicle starting under zero initial conditions, the number of spans a vehicle must cross to reach a steady-state condition depends on the number of modes and the traveling speed ratio of the vehicle. The maximum number of spans a vehicle must cross to reach a steady state is less than 100 , in accordance with calculated results. If the effects of guideway roughness are not considered, $Y_{0}$ and $\dot{Y}_{0}$ in Eq. 40 are assumed to be zero.

\subsection{Results of a SinglenSpan Guideway}

Figures 9 and 10 show the time histories of steady-state guideway displacement ratio and vehicle primary and secondary accelerations on the singlespan beam for two vehicle-traveling-speed ratios $\left(v / v_{c}=0.25\right.$ in Fig. 9 and $v / v_{c}=0.5$ in Fig, 10) when $\varepsilon=0.5, \gamma_{m}=0.1, \Omega=3, \gamma_{f}=0.25, \zeta_{n}=2 \%, \zeta_{p}=10 \%$, and $\zeta_{s}=25 \%$. The results show that dynamic interaction between vehicle and guideway (compare uncoupled vs. coupled curves) has relatively little influence on the secondary suspension at the given parameter values; the effect on guideway displacement is smaller for $\mathrm{v} / \mathrm{v}_{\mathrm{c}}=0.25$ than for $\mathrm{v} / \mathrm{v}_{\mathrm{c}}=0.5$, but the effect on the acceleration of the primary suspension is greater $f_{.} . \% / v_{c}=0.25$ than for $v / v_{c}=0.5$.

Figure 11 shows the influence of the vehicle-to-guideway mass ratio $\varepsilon=$ $\left(m_{p}+m_{S}\right) / m L$ on the maximum guideway displacement ratio $Y$ and maximum vehicle acceleration ratios $\ddot{Y}_{p}$ and $\ddot{Y}_{S}$ for both primary and secondary suspensions as a function of vehicle-traveling-speed ratio $\mathrm{v} / \mathrm{v}_{\mathrm{c}}$. With other vehicle/guideway parameters fixed, the ratio of the total vehicle mass to guideway mass has less effect on vehicle acceleration with respect to both the location of peaks and magnitudes than on guideway displacement. The location of maximum acceleration peaks occurs at about $0.5 \mathrm{v} / \mathrm{v}_{\mathrm{c}}$, which is dependent on the system frequency ratio $\Omega$ and vehicle mass ratio $\gamma_{m}$. However, as the mass ratio decreases, the maximurn guideway displacement ratio (at midspan) increases. If the mass ratio is small enough, or $\mathrm{v} / \mathrm{v}_{\mathrm{c}}<0.4$, the guideway deflection approaches that of an uncoupling situation; this is attained when vehicle acceleration forces are much smaller than the constant force due to the vehicle weight, so that the acceleration forces of the vehicle do not affect guideway motion. This indicates that, wiin a vehicle of small mass, dynamic motions of the vehicle and guideway can be decoupled, the vehicle can be considered a moving force on the guideway, and guideway deflection is then used as a known displacement input into the suspension. 

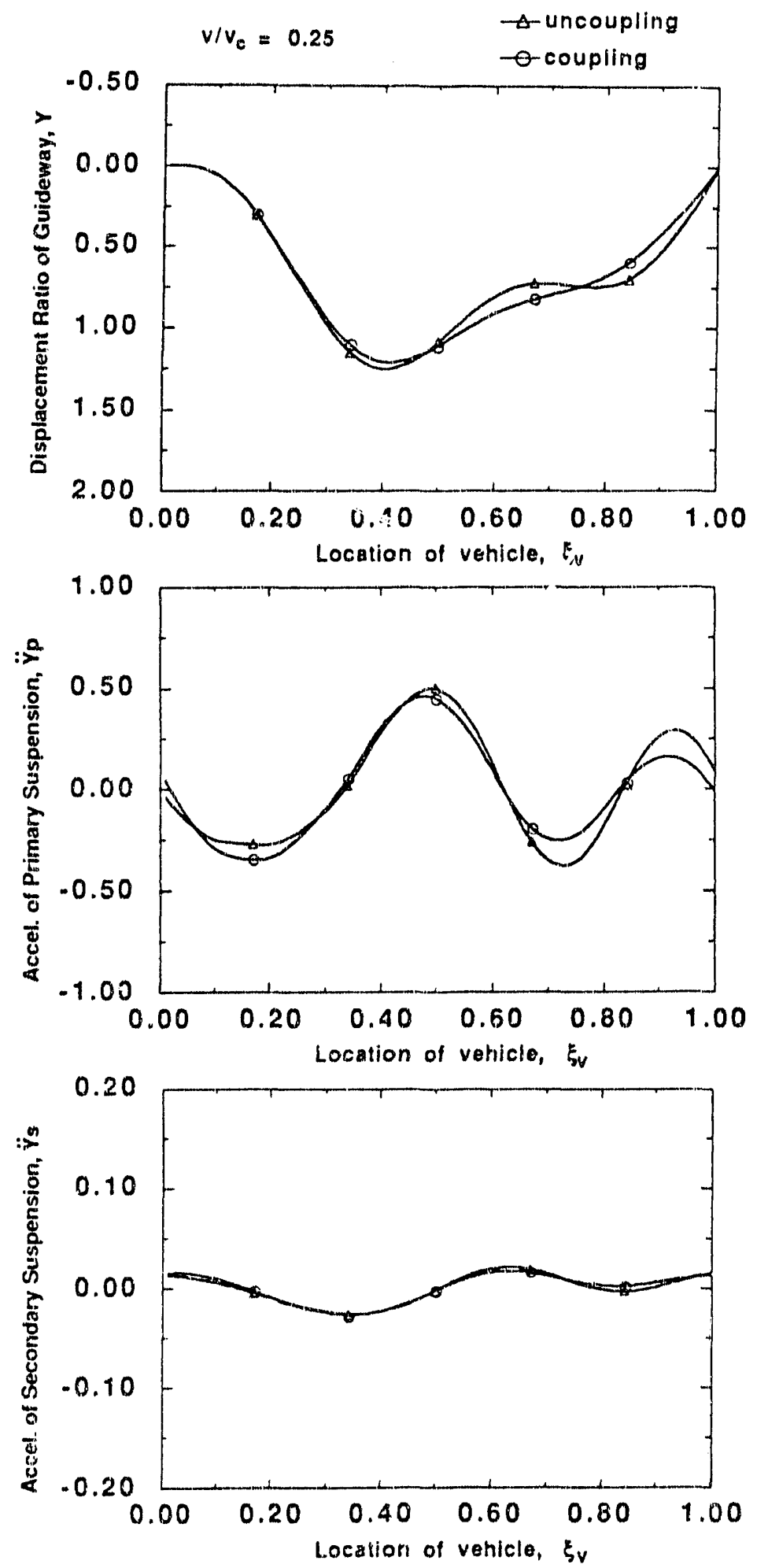

Fig. 9. Time histories of steady-state guideway displacement ratio and vehicle acceleration with speed ratio $v / v_{c}=0.25$ and system parameters $\varepsilon=$ $0.5, \gamma_{m}=0.1, \Omega=3, \gamma_{f}=0.25, \zeta_{n}=2 \%, \zeta_{p}=10 \%$, $\zeta_{s}=25 \%$ 

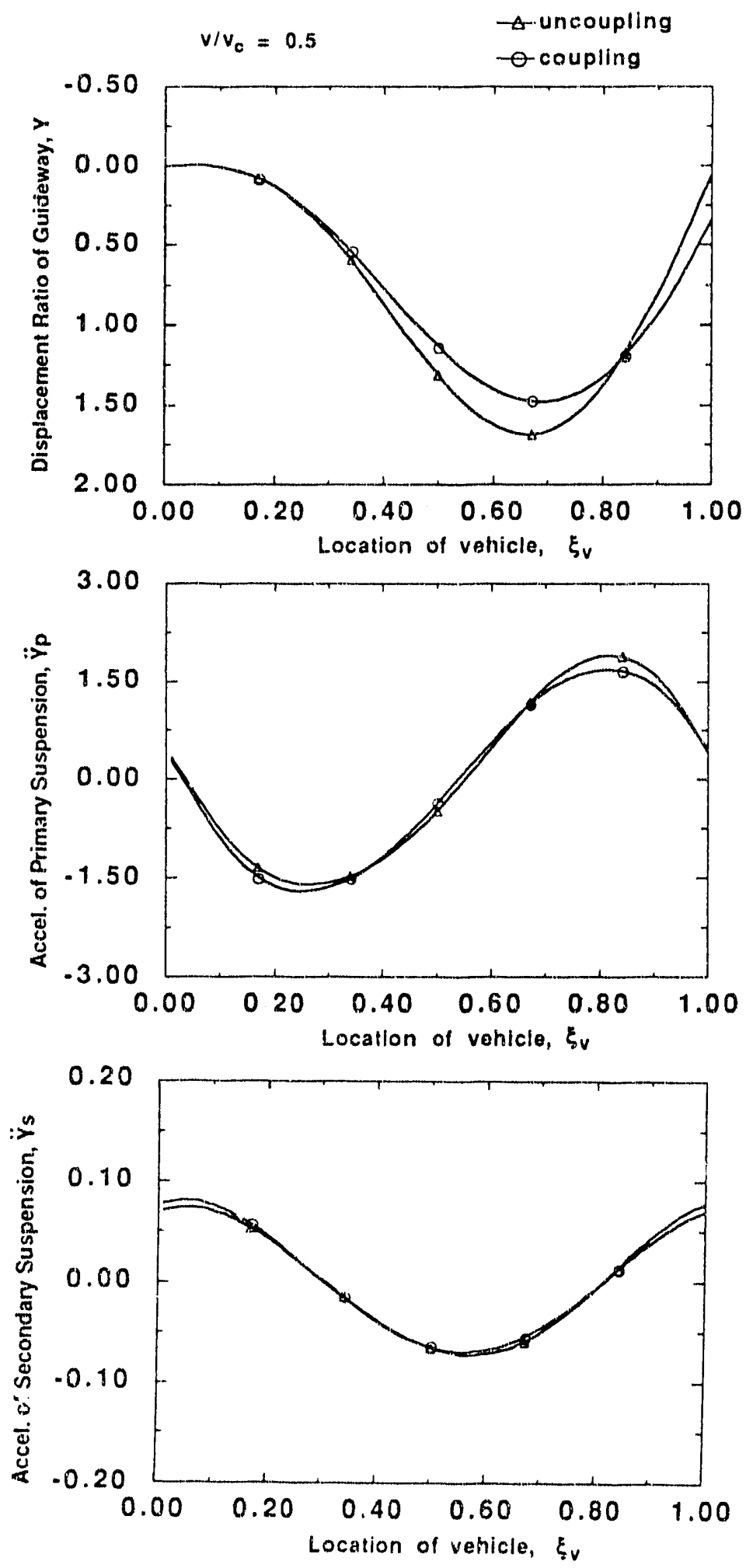

Fig. 10. Time histories of steady-state guideway displacement ratio and vehicle acceleration with speed ratio $v / v_{c}=0.5$ and system parameters $\varepsilon=$ $0.5, \gamma_{m}=0.1, \Omega=3, \gamma_{f}=0.25, \zeta_{n}=2 \%, \zeta_{p}=10 \%$, $\zeta_{\mathrm{s}}=25 \%$ 

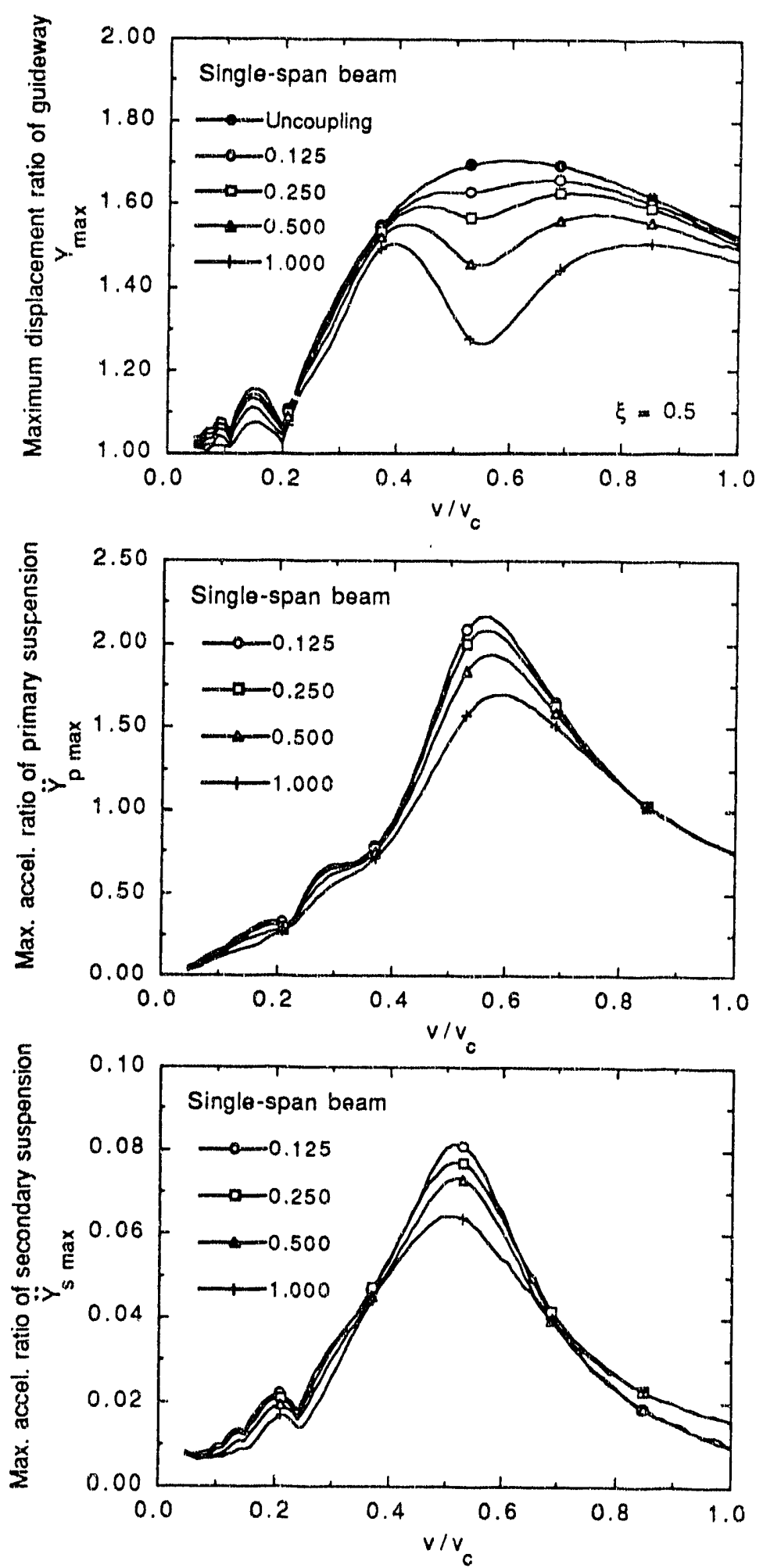

Fig. 11. Influence of mass ratio of vehicle to guideway on maximum guideway displacement and vehicle acceleration ratios with system parameters $\gamma_{m}=0.1, \Omega=3, \gamma_{f}=0.25, \zeta_{n}=2 \%$, $\zeta_{p}=10 \%, \zeta_{s}=25 \%$ 
Figure 12 shows the influence of vehicle primary-to-secondary-suspension mass ratio $\gamma_{m}$ on the maximum guideway displacement ratio $Y$ and vehicle acceleration ratios $\ddot{Y}_{p}$ and $\ddot{Y}_{s}$. Obviously, $\gamma_{m}$ affects the locations and magnitudes of the acceleration peaks. As $\gamma_{m}$ decreases, there are some characteristics to be noted: the location of the peak acceleration moves forward as $\mathrm{v} / \mathrm{v}_{\mathrm{c}}$ increases; the influence of $\gamma_{\mathrm{m}}$ on guideway deflection is reduced (for $\gamma_{\mathrm{m}}=0.2$, decoupling of interaction is acceptable wlien $\mathrm{v} / \mathrm{v}_{\mathrm{c}} \leq 0.3$; for $\gamma_{\mathrm{m}}=0.05$, decoupling of interaction is acceptable when $\mathrm{v} / \mathrm{v}_{\mathrm{c}} \leq 0.5$ ); and maximum deflection approaches the decoupled situation while the magnitude of the acceleration of the primary suspension increases.

Figure 13 illustrates the influence of vehicle/guideway frequency ratio $\Omega$ on the guideway displacement ratios and vehicle acceleration ratios. As $\Omega$ increases, acceleration magnitudes of both primary and secondary suspensions decrease and maximum guideway deflection approaches that of an uncoupling situation. Figure 14 shows the influence of vehicle frequency ratio $\gamma_{\mathrm{f}}$. With other parameters maintained constant, $\gamma_{f}$ only affects the magnitude of guideway deflection and vehicle acceleration ratios but not the location of peaks.

Figures 15 and 16 show the influence of vehicle damping ratios $\zeta_{\mathrm{p}}$ and $\zeta_{\mathrm{s}}$, respectively; both affect guideway deflection and vehicle acceleration ratios, but $\zeta_{\mathrm{s}}$ has more effect on primary and secondary acceleration.

In summary, certain vehicle/guideway parameters are of particular interest in the analysis of vehicle/guideway interactions. Decreasing $\varepsilon$ and $\gamma_{m}$ and increasing $\Omega$ and $\gamma_{\mathrm{f}}$ tends to reduce the dynamic interaction between vehicle and guideway. In general, if $\varepsilon \leq 0.25, \gamma_{\mathrm{m}} \leq 0.1$, and $\Omega>3$ when the vehicle traveling speed ratio $\mathrm{v} / \mathrm{v}_{\mathrm{c}}<0.5$, vehicle/guideway interactions can be neglected. To reduce vehicle heave acceleration and obtain better ride quality, it is wise to increase $\Omega$, decrease $\gamma_{\mathrm{f}}$, and increase $\zeta_{\mathrm{p}}$.

\subsection{Results of a Double-Span Guideway}

Figure 17 shows the influence of the vehicle/guideway mass ratio $\varepsilon=$ $\left(m_{p}+m_{s}\right) / m L$ on the maximum guideway displacement ratio $\mathrm{Y}$ and maximum vehicle acceleration ratio $\ddot{Y}_{p}$ and $\ddot{Y}_{S}$ for both primary and secondary suspensions as a function of vehicle-traveling-speed ratio $v / v_{c}$ on a double-span guideway. As we can see, the influence of mass ratio on the maximum guideway displacement ratio is similar to that of a single-span guideway. As the mass ratio decreases, the maximum guideway displacement ratio increases; when the mass ratio is small enough, the guideway deflection approaches that of an uncoupling situation. When the traveling speed ratio $\mathrm{v} / \mathrm{v}_{\mathrm{c}}<0.4$ for the middle location of the 

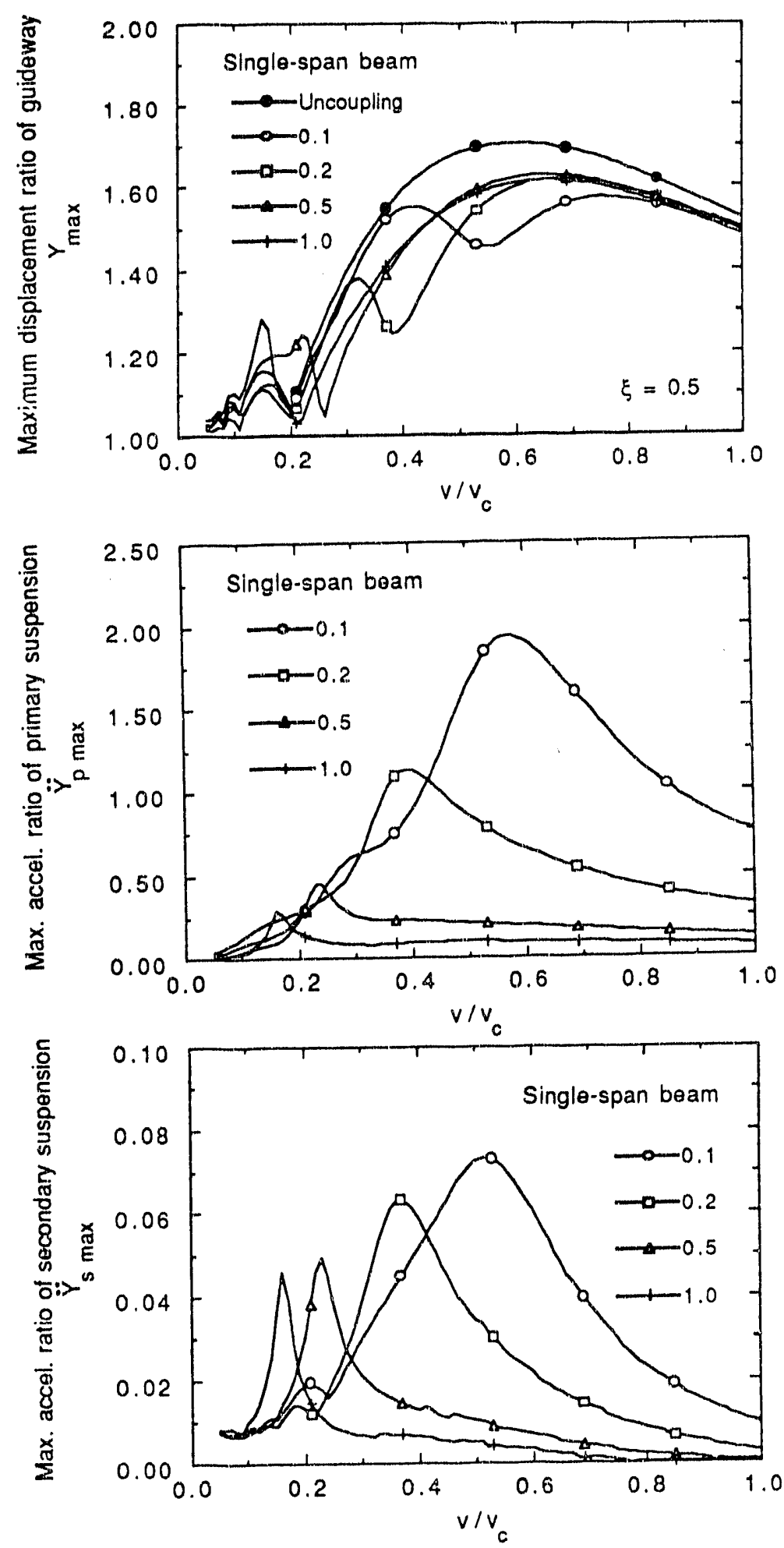

Fig. 12. Influence of mass ratio of primary to secondary suspensions on maximum guideway displacement and vehicle acceleration ratios with system parameters $\varepsilon=0.5, \Omega=3, \gamma_{f}=0.25, \zeta_{n}=2 \%$, $\zeta_{p}=10 \%, \zeta_{s}=25 \%$ 

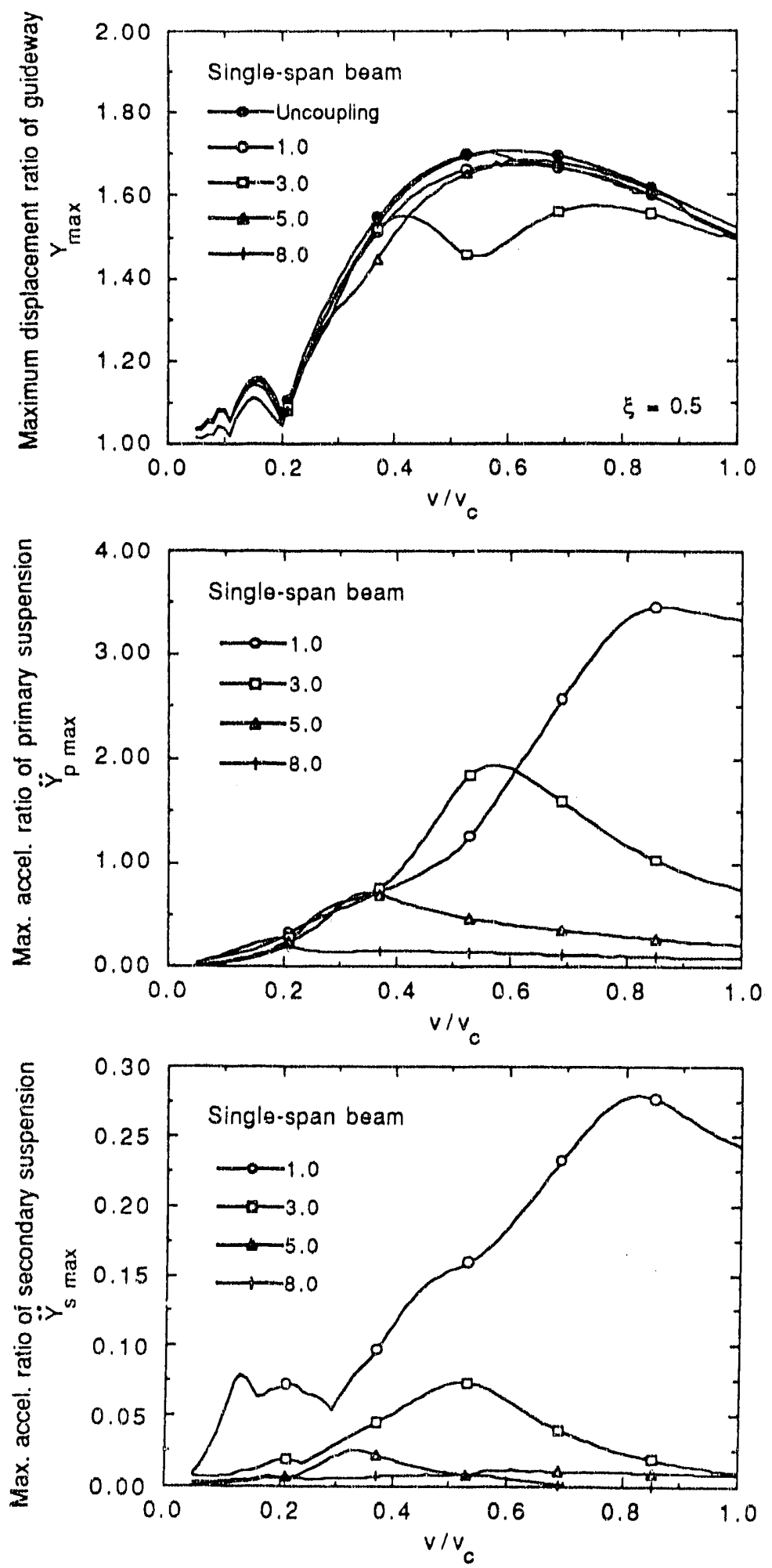

Fig. 13. Influence of vehicle/guideway frequency ratio on maximum guideway displacement and vehicle acceleration ratios with system parameters $\varepsilon=0.5, \Omega=3, \gamma_{m}=0.1, \gamma_{f}=0.25, \zeta_{n}=2 \%, \zeta_{p}=$ $10 \%, \zeta_{s}=25 \%$ 

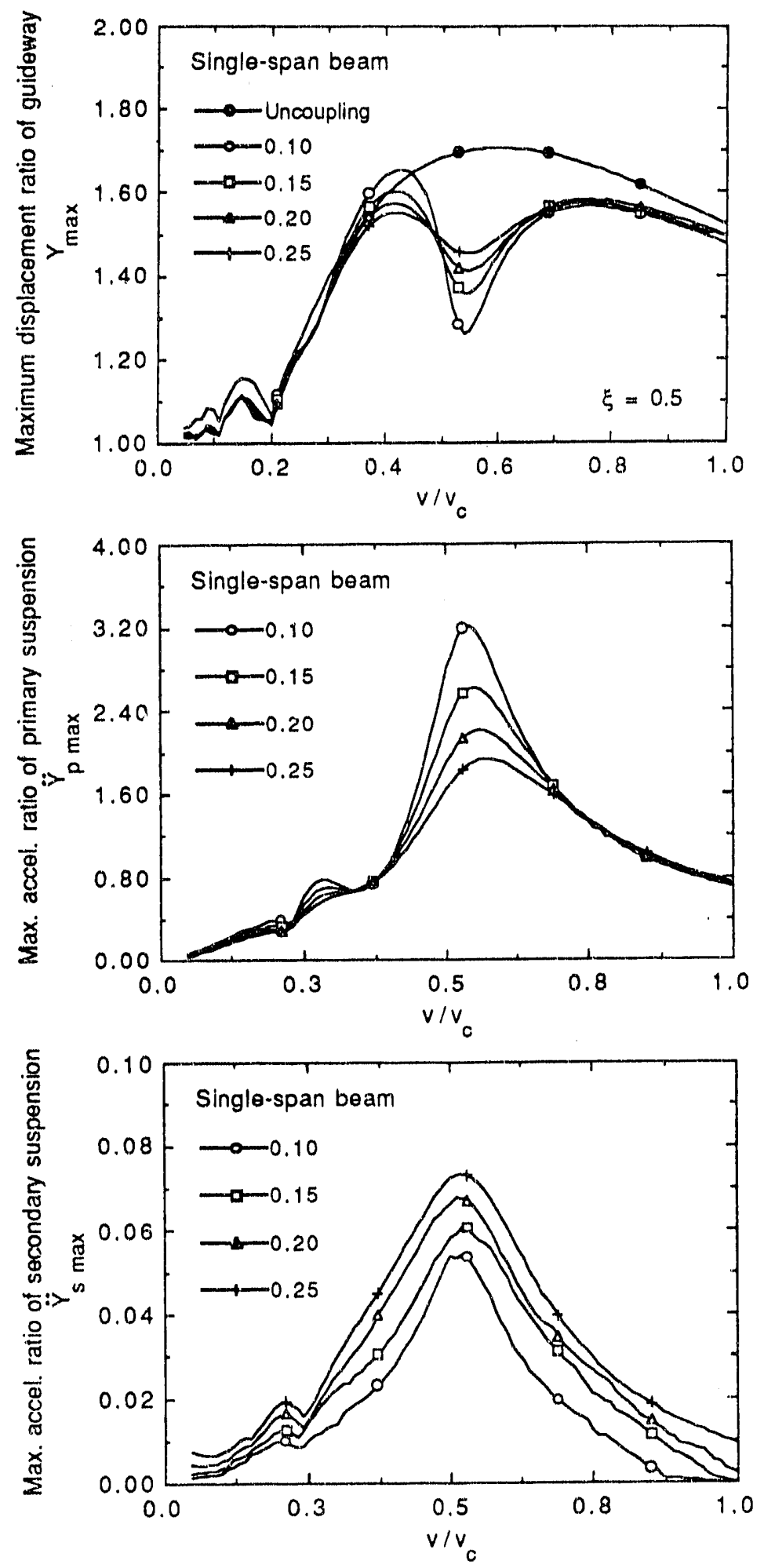

Fig. 14. Influence of frequency ratio of secondary to primary suspension on maximum guideway displacement and vehicle acceleration ratios with system parameters $\varepsilon=0.5, \Omega=3, \gamma_{m}=0.1$, $\zeta_{n}=2 \%, \zeta_{p}=10 \%, \zeta_{s}=25 \%$ 


\section{8}
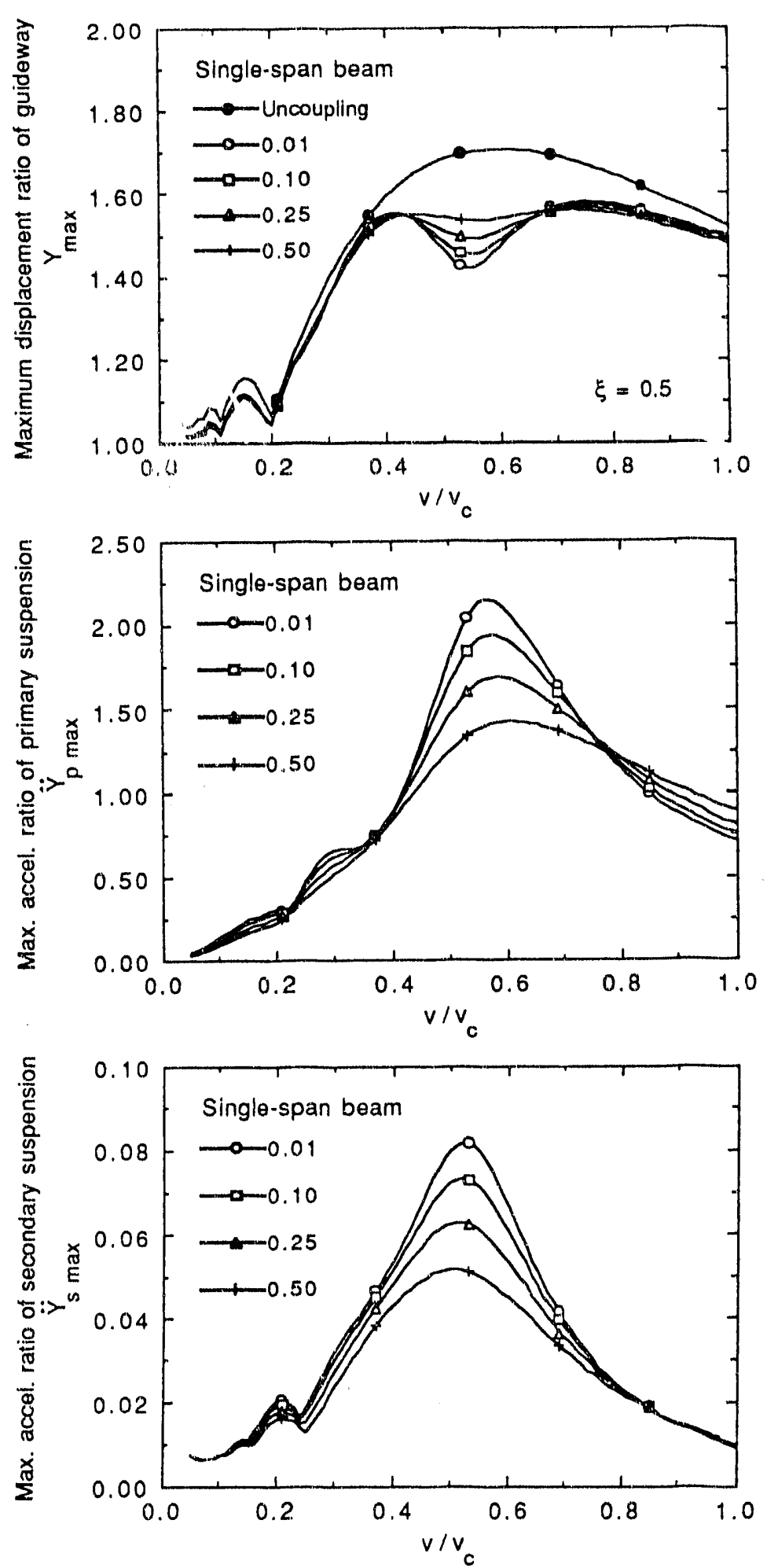

Fig. 15. Influence of damping ratio of primary suspension on maximum guideway displacement and vehicle acceleration ratios with system parameters $\varepsilon=0.5, \gamma_{m}=0.1, \Omega=3, \gamma_{f}=$ $0.25, \zeta_{n}=2 \%, \zeta_{s}=25 \%$ 

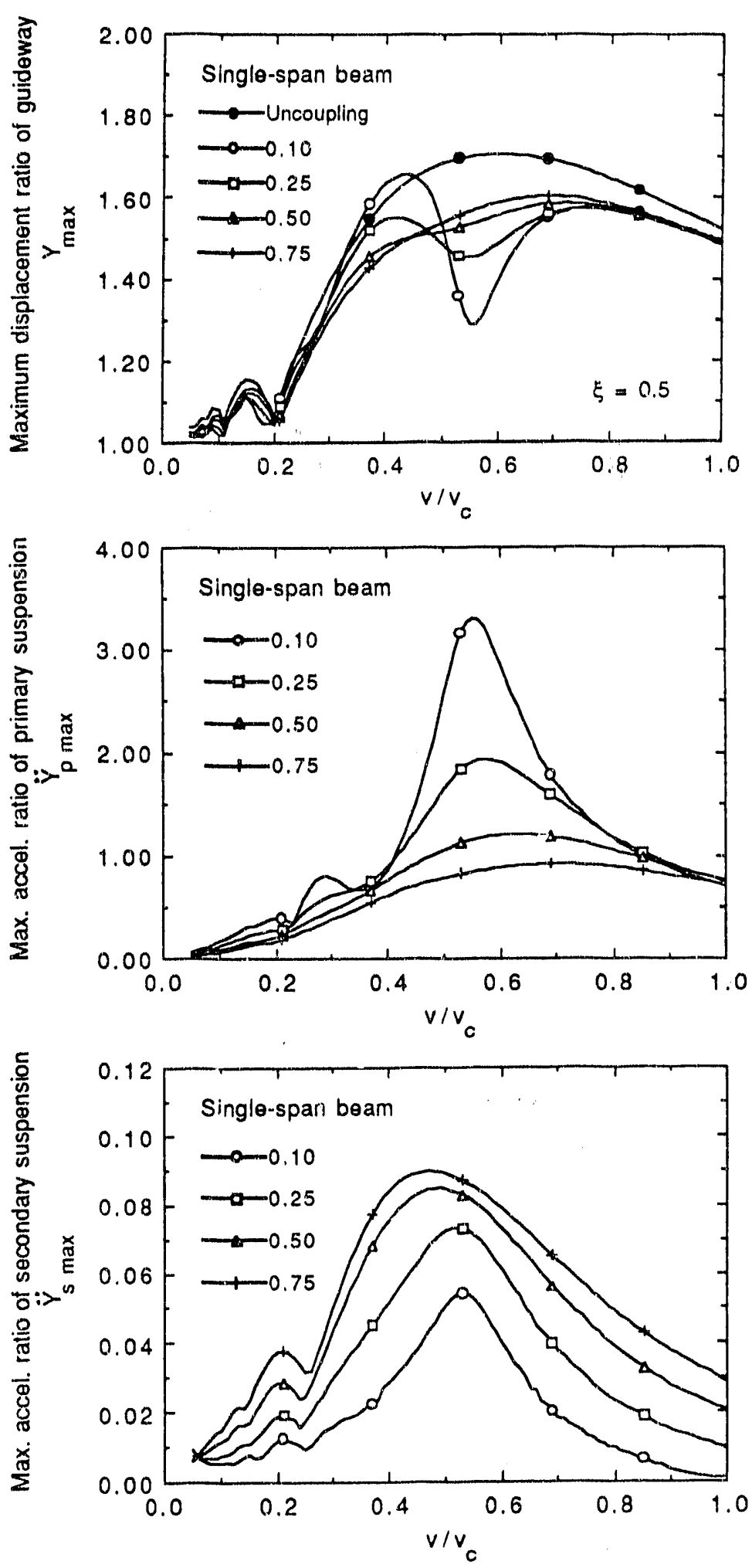

Fig. 16. Influence of damping ratio of secondary suspension on maximum guideway displacement and vehicle acceleration ratios with system parameters $\varepsilon=0.5, \gamma_{m}=0.1, \Omega=3, \gamma_{f}=$ $0.25, \zeta_{n}=2 \%, \zeta_{p}=10 \%$ 

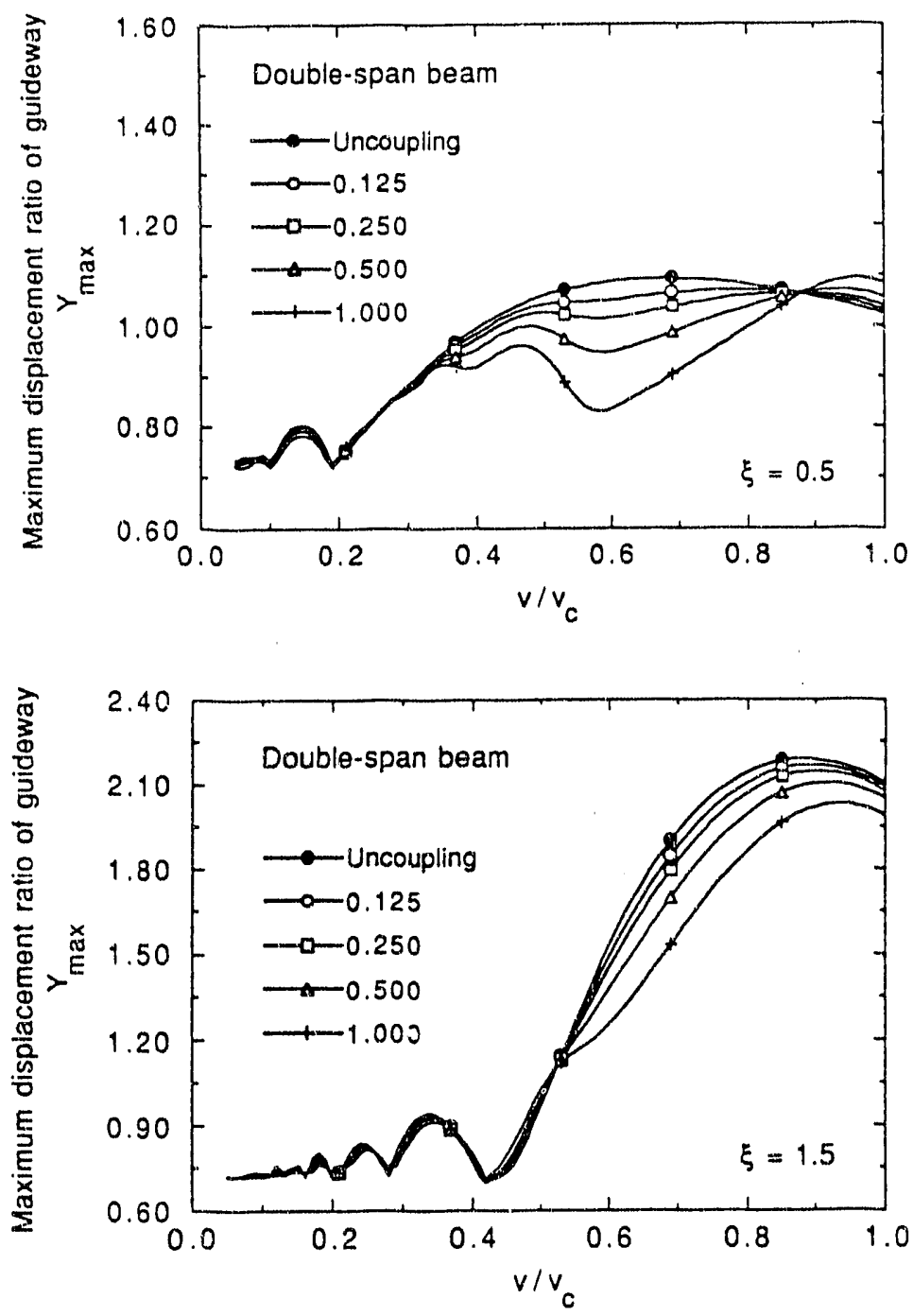

Fig. 17. Influence of mass ratio of vehicle/guideway on maximum guideway displacement and vehicle acceleration ratios on a double-span beam with sysiem parameters $\gamma_{m}=0.1, \Omega=3, \gamma_{f}=0.25$, $\zeta_{n}=2 \%, \zeta_{p}=10 \%, \zeta_{s}=25 \%$ 


\section{1}
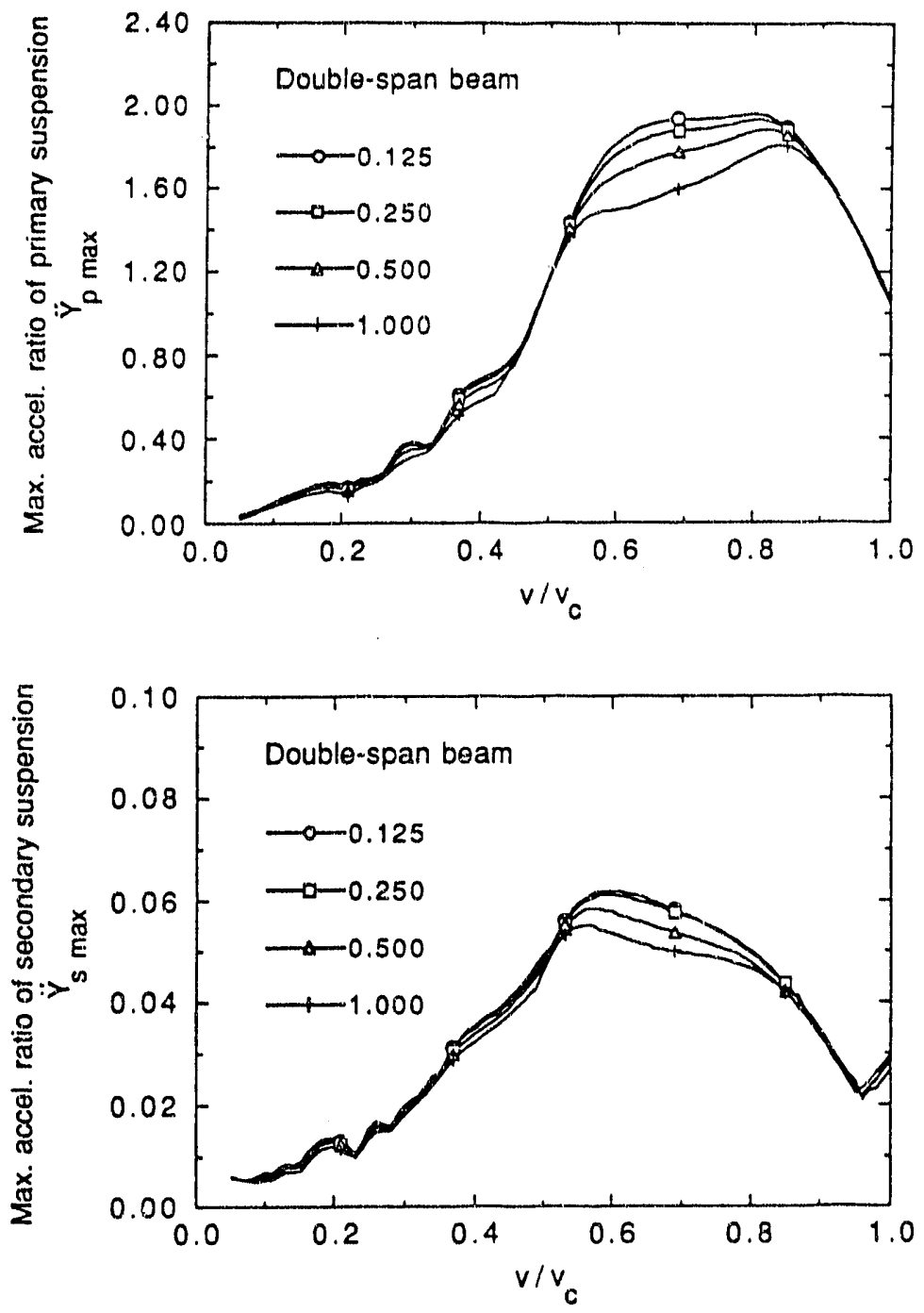

Fig. 17. (Cont'd) 
first $\operatorname{span}(\xi=0.5)$ and $v / \mathrm{v}_{\mathrm{c}}<0.55$ for the middle location of the second span $(\xi=$ 1.5), no matter what the mass ratio is, the guideway deflection approaches that of the moving force. The dynamic interaction affects the jeflection less on the second span than that on the first span for the double-span guideway. With given parameter values, the mass ratio has less effect on vehicle accelerations, which is similar to the situation of a single-span guideway.

Figure 18 shows the comparison of single-span and double-span guideways. The response characteristics of the maximum guideway displacement are similar to those in Figure 6 when a moving force is traveling in the guideway. When the vehic a-traveling-speed ratio $\mathrm{v} / \mathrm{v}_{\mathrm{c}}<0.5$, the maximum displacement ratios at both $\xi=0.5$ and $\xi=1.5$ for the double-span guideway are much smaller than those of the single-span guideway. The differences between uncoupling and coupling models for the double-span guideway are smaller than those of the single-span guideway. From compariscns of vehicle accelerations, the amplitudes of maximum accelerations of both primary and secondary suspension for the double-span guideway are lower than those of the single-span guideway; this again indicates that a double-span guideway might provide a better ride quality.

\subsection{Effects of Guideway Surface Irregularities}

The surface irregularities of the guideway are very important to the ride quality of maglev systems. These irregularities may be caused by imperfections in manufacturing and assembling of the structural components, thermal effects, or surface wear. In practice, guideway surface irregularities make up an important input to maglev vehicles. In the study of vehicle/guideway interaction, the surface irregularities can be considered in Eq. 17. For a simple case, we define the function of surface irregularities as

$$
y_{0}(x)=d \sin \pi \ell_{0} x
$$

or

$$
Y_{o}(\xi)=\frac{y_{0}(x)}{y_{m}}=r_{d} \sin \pi r_{\ell} \xi
$$

where 

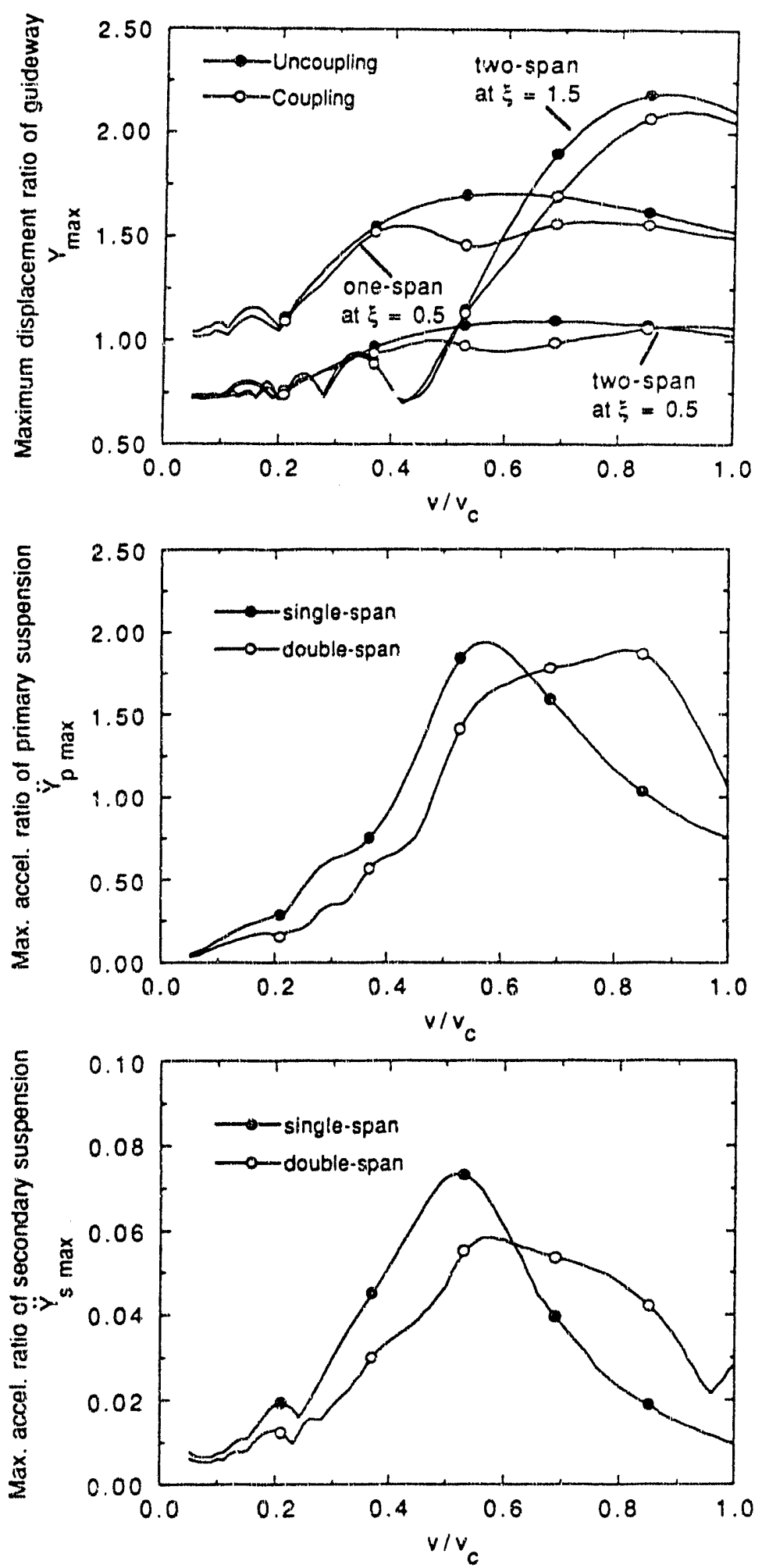

Fig. 18. Comparison of single-span and double-span beams on maximum guideway displacement and vehicle acceleration ratios with syitem parameters $\varepsilon=0.5, \gamma_{m}=0.1, \Omega=3, \gamma_{f}=0.25$, $\zeta_{n}=2 \%: \zeta_{n}=10 \% . \zeta_{s}=25 \%$ 


$$
\begin{aligned}
& r_{d}=\frac{d}{y_{m}}=\frac{d}{\frac{2\left(m_{p}+m_{s}\right) g}{m L \omega_{1}^{2}}} \\
& r_{\ell}=\ell_{0} / L
\end{aligned}
$$

$d$ is surface-irregularity depth and $\ell_{0}$ is surface-irregularity length (see Fig. 8), and $r_{d}$ is surface-irregularity depth ratio and $r_{\ell}$ is surface-irregularity length ratio. Assume that the irregularity length has some relation to the frequency of guideway, e.g.,

$$
\mathrm{k} \Omega=\pi \mathrm{r}_{\ell} .
$$

We can rewrite Eq. 42 as

$$
\mathrm{Y}_{0}(\xi)=\mathrm{r}_{\mathrm{d}} \sin \mathrm{k} \Omega \xi \text {. }
$$

Using Eqs. 38, 39, and 40, we studied effects of guideway surface irregularity on the vehicle motion. Figures 19 and 20 show both accelerations of primary and secondary suspension versus traveling speed ratiu $\mathrm{v} / \mathrm{v}_{\mathrm{c}}$ for different surfaceirregularity depth and length ratios, respectively.

In Fig. 19, as irregularity depth ratio increases, the maximum acceleration ratio of vehicle increases when traveling speed ratio is $>0.5$. Figure 20 presents the effect of irregularity length ratio. As irregularity length ratio increases $(\mathrm{k}=$ $\pi r_{\ell} / \Omega$ increases), the maximum acceleration ratio of vehicle increases. When $k=$ 50 , the accelerations of both primary and secondary suspensions exceed much of that when $\mathrm{k}=0$, in particular, the region of traveling speed ratio $\mathrm{v} / \mathrm{v}_{\mathrm{c}}<0.6$. Because the practical traveling speed ratio of maglev system is $<0.5$, irregularity length ratio will affect the ride quality more than irregularity depth ratio. These results indicate that the surface irregularities should play an important role in the guideway design for maglev systems.

\section{Vehicle/Guideway Interaction in Transrapid Maglev System}

The German Transrapid maglev system is an electromagnetic system (EMS) based on the principle of attraction in magnetism. The approach uses conventional electromagnets on the vehicle, which are attracted upward toward ferromagnetic rails above the magnets (see Fig. 21). The suspension of a vehicle by attractive magnetic forces is inherently unstable and consequently it is continuously adjusted by the strength of the suspending electromagnet. This 

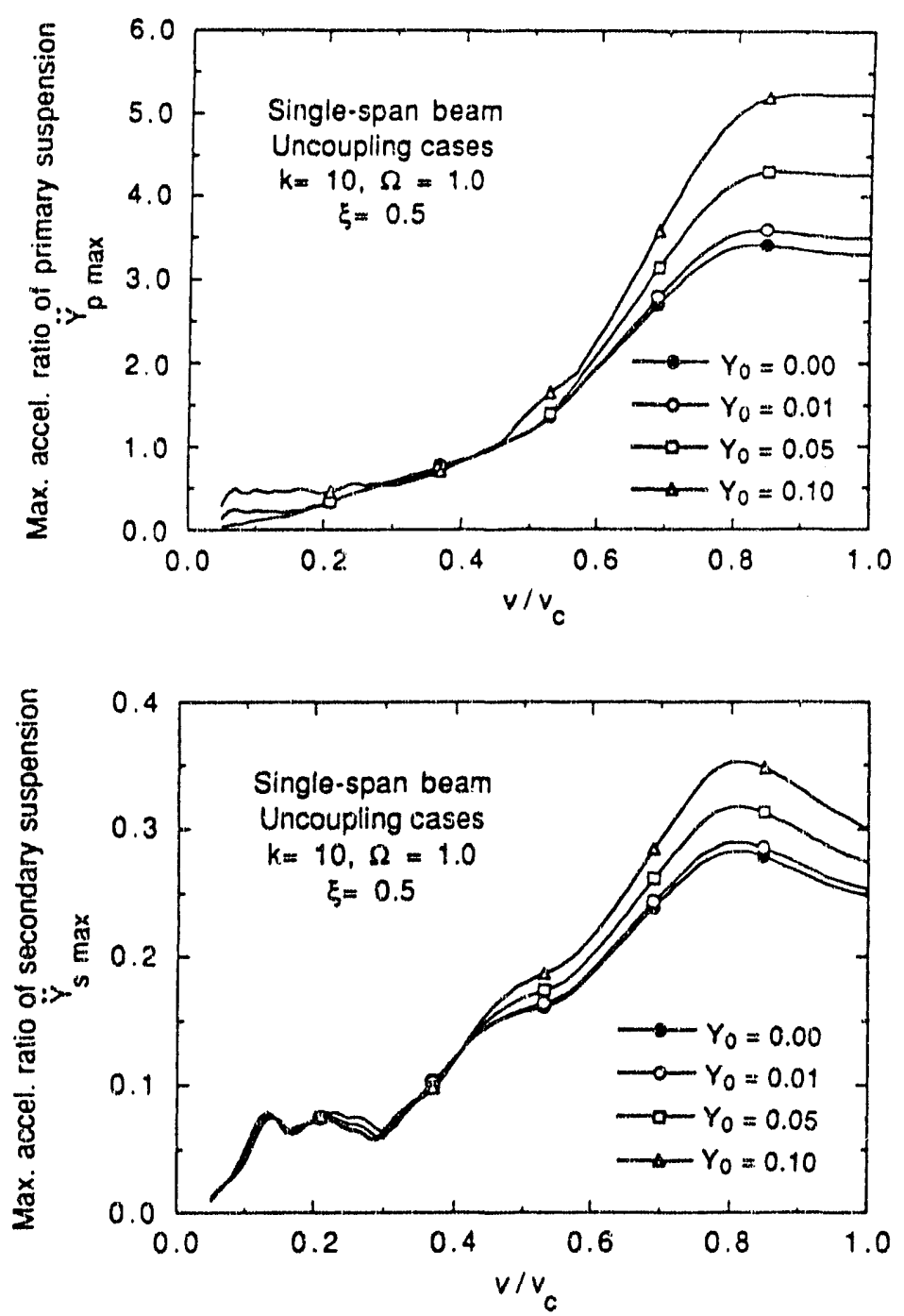

Fig. 19. Effect of surface irregularity depth ratio of guideway on maximum vehicle accelerations with system parameters $\varepsilon=0.5, \gamma_{m}=0.1, \Omega=1$, $\gamma_{f}=0.25, \zeta_{n}=2 \%, \zeta_{p}=10 \%, \zeta_{s}=25 \%$ and coeficient $k=10$ 

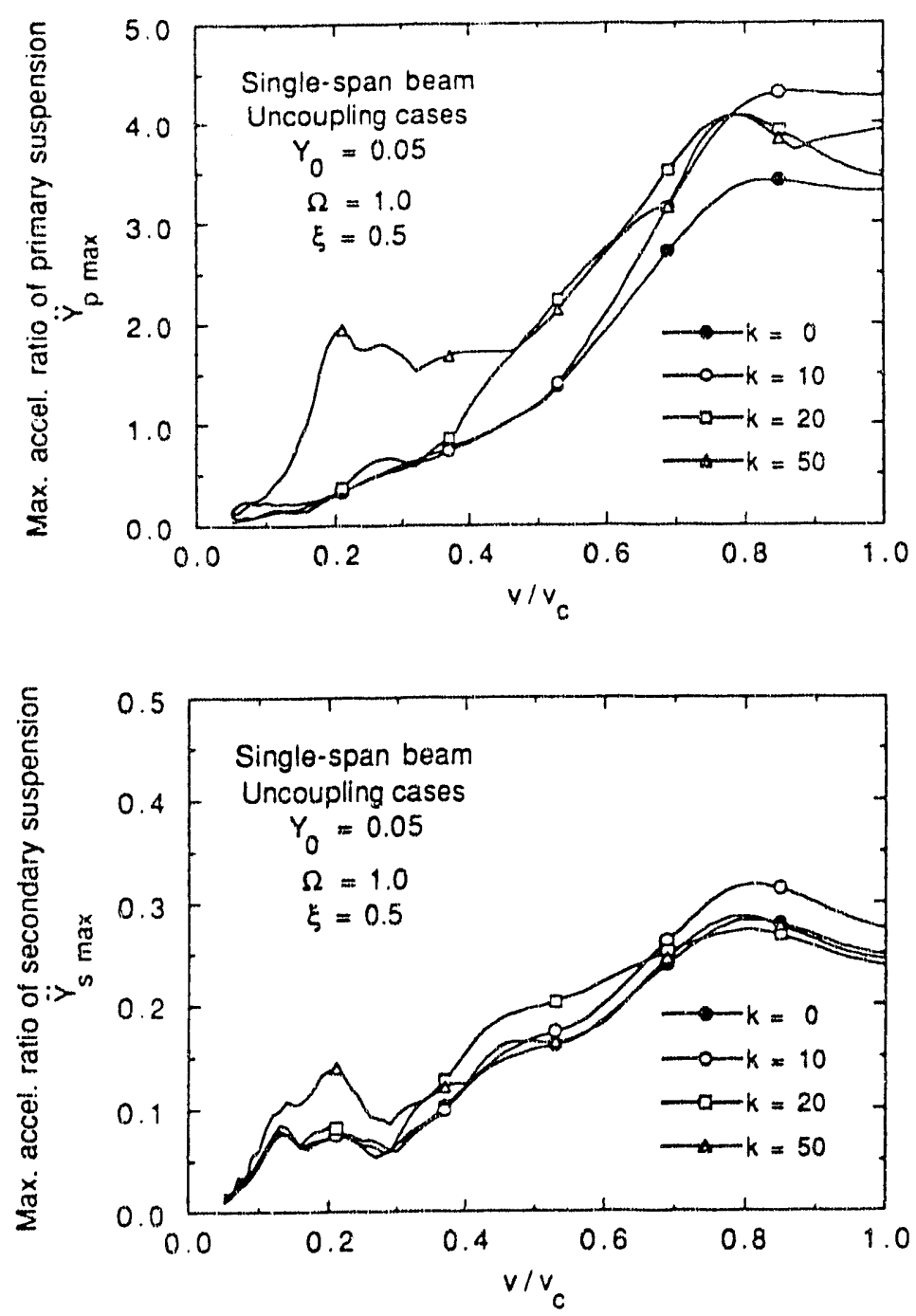

Fig. 20. Effect of surface irregularity length of guideway on maximum vehicle accelerations with system parameters $\varepsilon=0.5, \gamma_{m}=0.1, \Omega=1, \gamma_{f}=0.25$, $\zeta_{n}=2 \%, \zeta_{p}=10 \%, \zeta_{s}=25 \%$ and surface irregularity depth ratio $r_{d}=0.05$ 


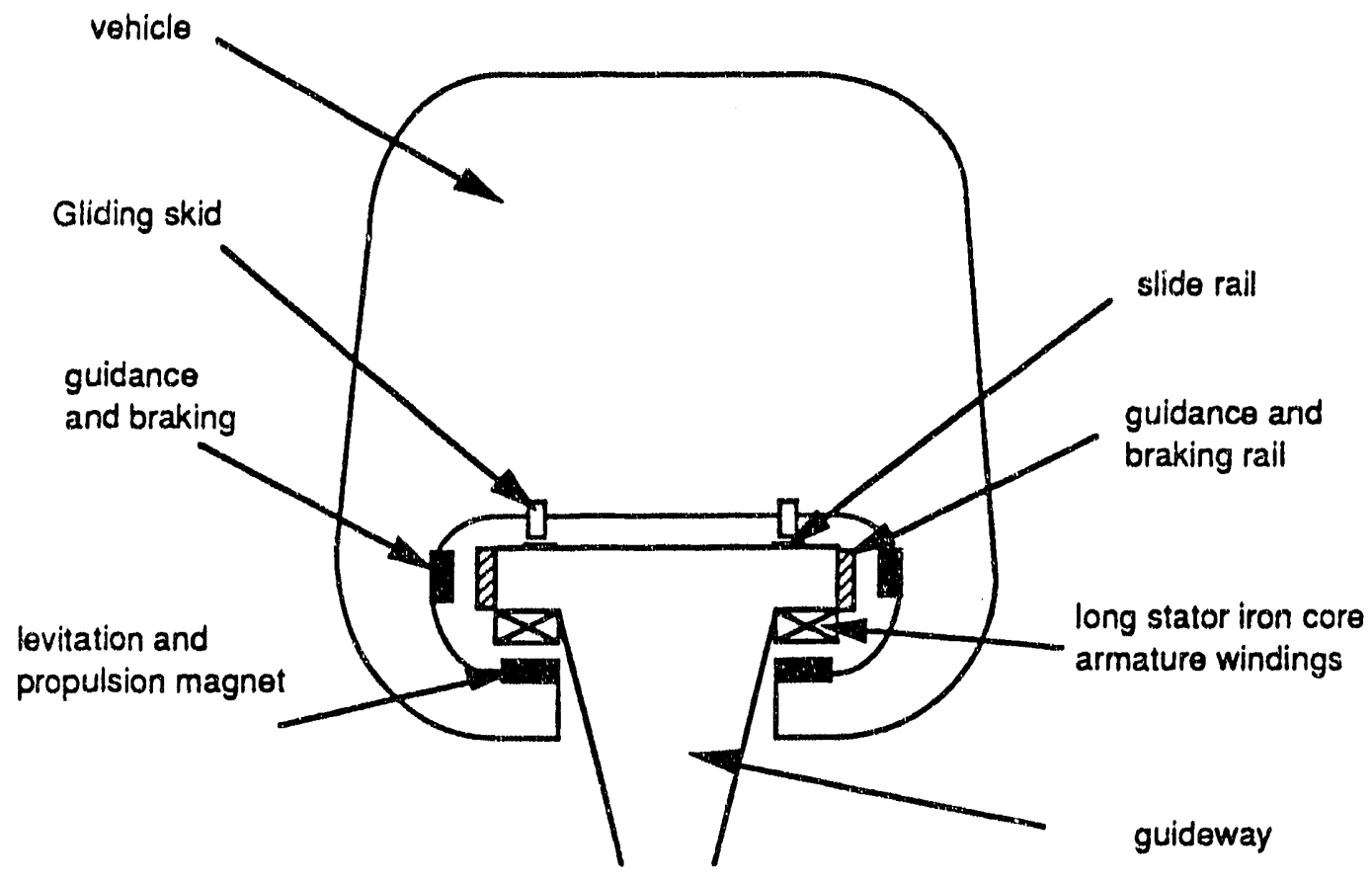

Fig. 21. Sketch of Transrapid maglev system

system has been under development for about 20 years. More than a dozen prototype vehicles have been developed and tested during this period. In particular, the development of full-scale application-type vehicles Transrapid 06 and Transrapid 07, or TR06 and TR07, in 1983 and 1988, respectively, has earned worldwide recognition. This technology is almost ready for revenue-application service. TR06 attained a maximum speed of $412.5 \mathrm{~km} / \mathrm{h}$ on its $31.5-\mathrm{km}-\mathrm{long}$ Emsland test track in January 1988 (He et al. 1992).

In this study, we tried to use a two-degree-of-freedom dynamic model to evaluate the effects of vehicle/guideway interaction in the Transrapid system. Because TR07 data are rarely found in the literature, we analyzed only the TR06 system with the limited data from Bohn and Steinmetz (1985).

\subsection{System Parameter Values}

The guideway system in Emsland was built in two parts, one with singlespan concrete beams and the other with double-span steel beams. Selected data are given in Table 1.

The TR06 vehicle consists of a two-car section; selected data are summarized in Table 2. 
Table 1. Beam data for Emsland guideway

\begin{tabular}{lccc}
\hline Beam & $\begin{array}{c}\text { Length, } \\
\mathrm{m}\end{array}$ & $\begin{array}{c}\text { Weight, } \\
\mathrm{kN} / \mathrm{m}\end{array}$ & $\begin{array}{c}\text { Eigenfrequency, } \\
\mathrm{Hz}\end{array}$ \\
\hline Concrete & 24.858 & 36.8 & 6.5 \\
Steel & 49.708 & 15.5 & 6.6 \\
\hline
\end{tabular}

Table 2. TRO6 vehicle data

\begin{tabular}{lc}
\hline Length, m & 54.2 \\
Width, m & 3.7 \\
Height, m & 4.2 \\
Track gauge, m & 2.8 \\
Net weight (two cars), t & 102.4 \\
Payload (196 passengers), t & 20
\end{tabular}

The basic element of the EMS suspension is the electromagnet system, which suspends the vehicle without contact by attracting forces to the rails at the guideway. To obtain good ride comfort and low dynamic energy losses, each magnet is fixed to the bogies by spring and damping elements. Furthermore, the passenger cabin is suspended by the secondary suspension from jointed, coupled bogies. Suspension system data are given in Table 3 .

Table 3. TRO6 suspension system data

\begin{tabular}{ll}
\hline Primary suspension & \\
- eigenfrequency, $\mathrm{Hz}$ & 0.4 \\
- relative damping rate & \\
Secondary suspension & 0.8 \\
- eigenfrequency, $\mathrm{Hz}$ & 0.3 \\
- relative damping rate & 32 \\
Net weight of suspension system, $\mathrm{t}$ & 19.2 \\
Net weight of passenger cabin, $\mathrm{t}$ & \\
\hline
\end{tabular}

With the above data, we can calculate the parameter values applied in our dynamic model as

$$
\begin{aligned}
\varepsilon & =1.56 & & \text { (for steel beam }) \\
& =0.656 & & (\text { for concrete beam })
\end{aligned}
$$




$$
\begin{aligned}
\Omega & =0.94 \quad \text { (for steel beam) } \\
& =0.93 \quad \text { (for concrete beam) } \\
\gamma_{\mathrm{m}} & =1.1 \\
\gamma_{\mathrm{f}} & =0.11 \\
\zeta_{\mathrm{p}} & =0.4 \\
\zeta_{\mathrm{s}} & =0.3 .
\end{aligned}
$$

And static deflection in the middle of span can be calculated as

$$
\begin{aligned}
& \delta=y_{m}=\frac{2\left(m_{p}+m_{s}\right) g}{m L \omega_{1}^{2}}=\frac{2 \varepsilon g}{\omega_{1}^{2}}=17.8 \mathrm{~mm} \quad \text { (for steel beam) } \\
& \delta=y_{m}=7.7 \mathrm{~mm} \quad \text { (for concrete beam), }
\end{aligned}
$$

and the bending rigidity of guideway structure $\mathrm{EI}$ is

$\mathrm{EI}=10.66 \times 10^{6} \mathrm{kN}-\mathrm{m}^{2} \quad$ (for steel beam)

$\mathrm{EI}=24.56 \times 10^{6} \mathrm{kN}-\mathrm{m}^{2} \quad$ (for concrete beam).

The design speed of the TR06 vehicle is $400 \mathrm{~km} / \mathrm{h}$. The traveling speed ratio is

$$
\begin{aligned}
& v_{r}=\frac{V}{2 L f_{1}}=0.3386 \quad \text { (for steel beam) } \\
& v_{r}=0.3438 \quad \text { (for concrete beam). }
\end{aligned}
$$

\subsection{Evaluation of Transrapid System}

Using parameter values of Transrapid calculated above, we performed many simulations for both the single-span concrete beam and docible-span steel beam.

Figures 22 and 23 show results of maximum displacement of guideway and maximum accelerations of primary and secondary suspensions for the singlespan concrete beam and double-span steel beam, respectively. From Fig. 22, we note that when the traveling speed ratio exceeds 0.2 , displacement at the middle 

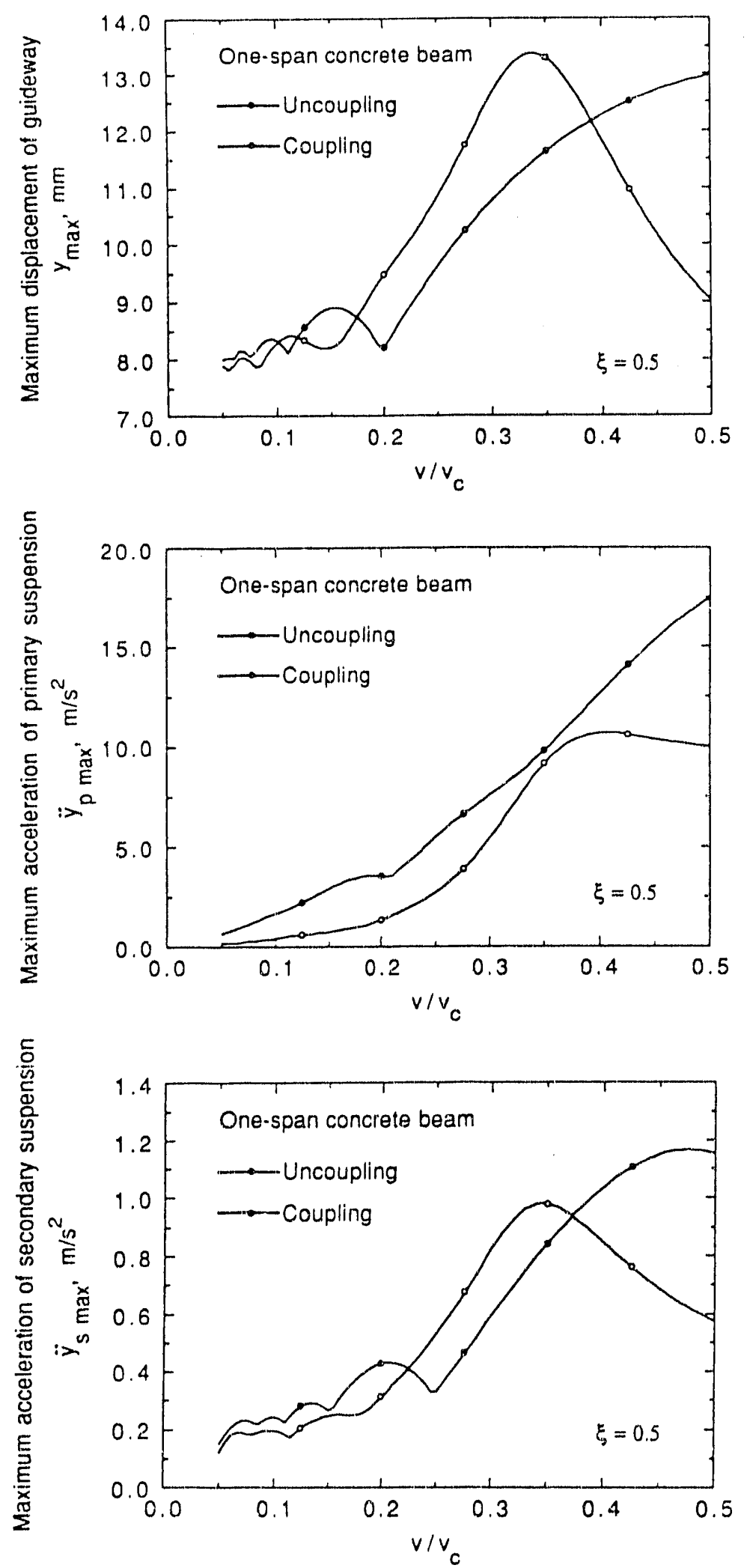

Fig. 22. Maximum guideway displacement and vehicle accelerations of Transrapid on a single-span concrete beam versus speed ratio 

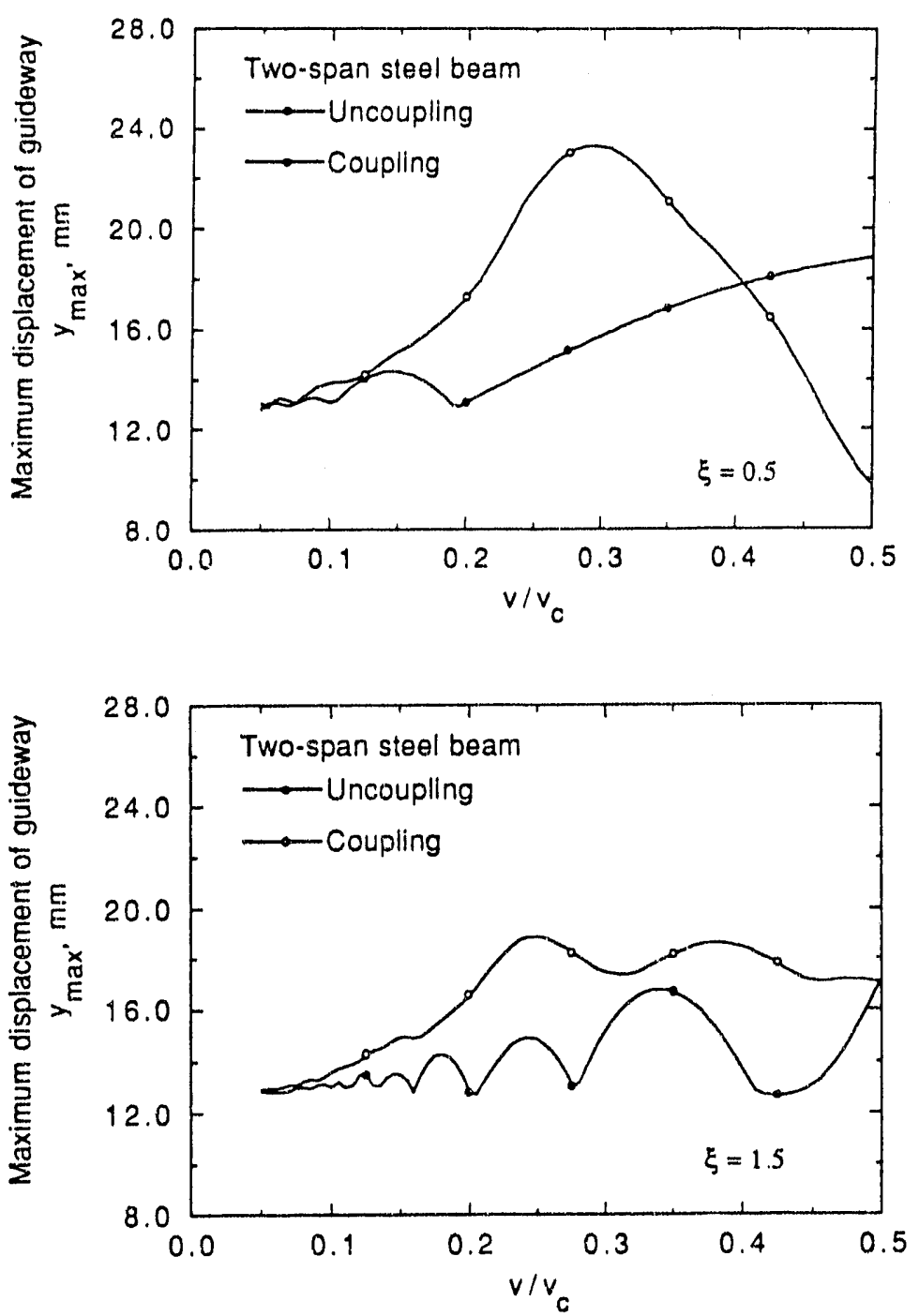

Fig. 23. Maximum guideway displacement and vehicle accelerations of Transrapid on a double-span steel beam versus speed ratio 

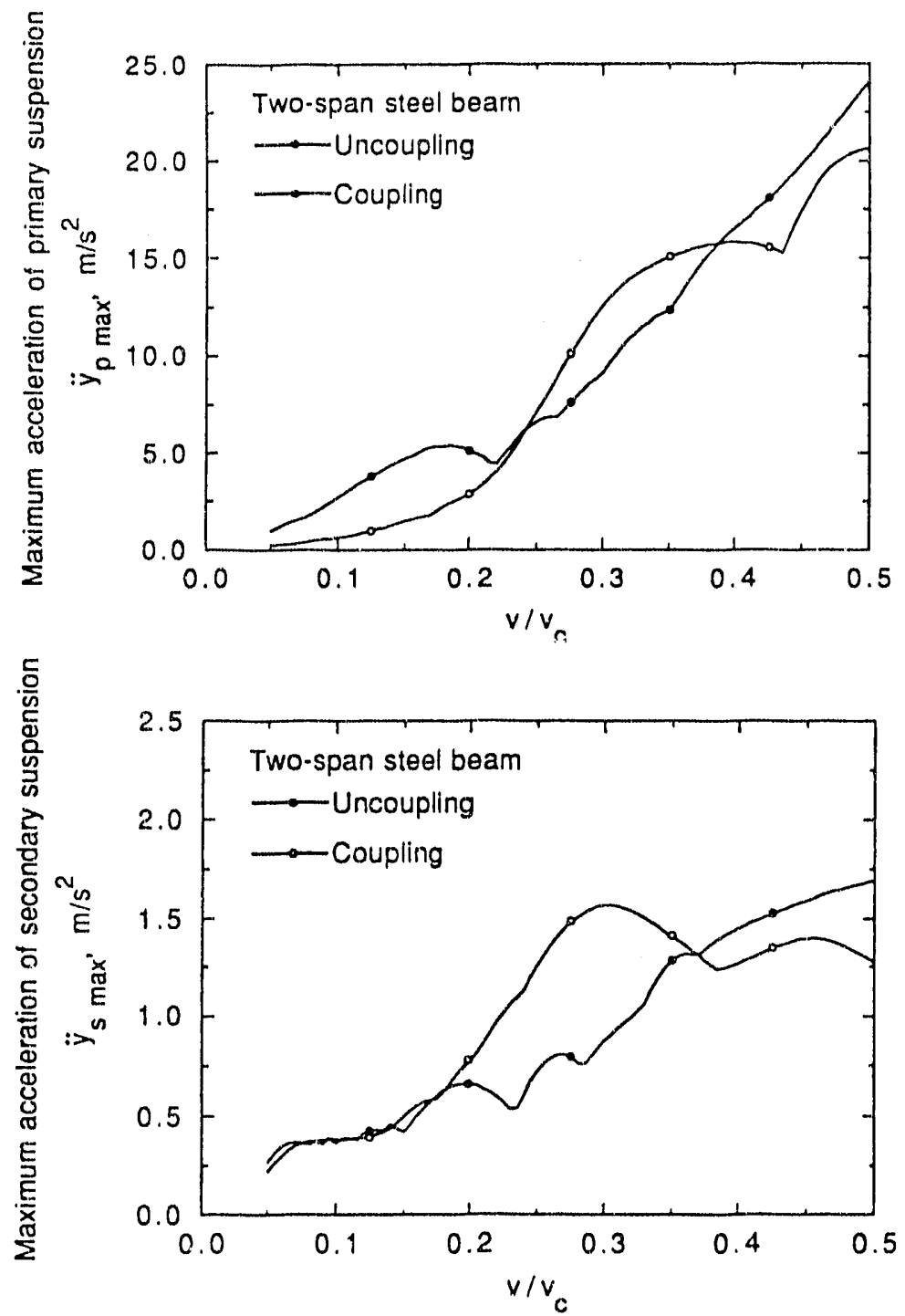

Fig. 23. (Cont'd) 
span for the single-span concrete beam increases with speed ratio. At $\mathrm{v} / \mathrm{v}_{\mathrm{c}}=0.35$, displacement amplitudes are much higher than those of static deflection $\delta=$ $7.7 \mathrm{~mm}$. Note that when speed ratio is $>0.2$, the displacement amplitude calculated with coupled models is larger than that calculated with an uncoupled model. The double-span steel guideway shows the same tendency as that of the single-span concrete guideway. Also, there are differences of accelerations of primary and secondary suspensions with coupled and uncoupled models. At the design vehicle speed region $\mathrm{v} / \mathrm{v}_{\mathrm{c}} \approx 0.35$, maximum accelerations of secondary suspension with the coupled model are higher than those with the uncoupled model for both concrete and steel guideways. From this point of view, dynamic interaction between vehicle and guideway indeed affects ride comfort when vehicle speed is high. These results apparently illustrate the very important fact that for the Transrapid system, vehicle dynamic loads on the guideway can be much higher than the weight of the vehicle, and vehicle/guideway interaction can neither be neglected nor analyzed with static equations. Furthermorc, guideway vibrations and oscillations can place large loads on the magnets and the control system and could have detrimental effects on the guideway.

Figures 24 and 25 show the time histories of steady-state guideway displacements and vehicle primary and secondary accelerations for both the single-span concrete guideway and the double-span steel guideway when the vehicle is assumed to be traveling at its design speed $v=400 \mathrm{~km} / \mathrm{h}$. Obviously, the amplitudes of guideway displacement and vehicle acceleration are much higher than expected. The vertical acceleration of secondary suspension is $>1.5 \mathrm{~m} / \mathrm{s}^{2}$ for the steel guideway and $>1.0 \mathrm{~m} / \mathrm{s}^{2}$ for the concrete guideway. The desirable vertical acceleration should be $<0.05 \mathrm{~g}$. In fact, the Transrapid system utilizes the magnetic suspension controller in a feedback pattern to maintain a constant air gap and reduce the vehicle's acceleration amplitudes. However, the dynamic vehicle/guideway interaction of the Transrapid system should be taken into account in future maglev system designs.

\section{Conclusions}

The dynamic interactions between vehicle and guideway in a maglev system have been investigated by modeling the vehicle both as a concentrated moving force traveling on the guideway and as a two-degree-of-freedom model.

For a moving force on a single-span or two-span beam, the dynamic deflections of simply supported guideway spans were evaluated for various combinations of constant and pulsating forces moving along the guideway. In this case, traveling speeds of the moving force play a very important role in beam response characteristics. Maximum deflection of the beam and the location of the moving 

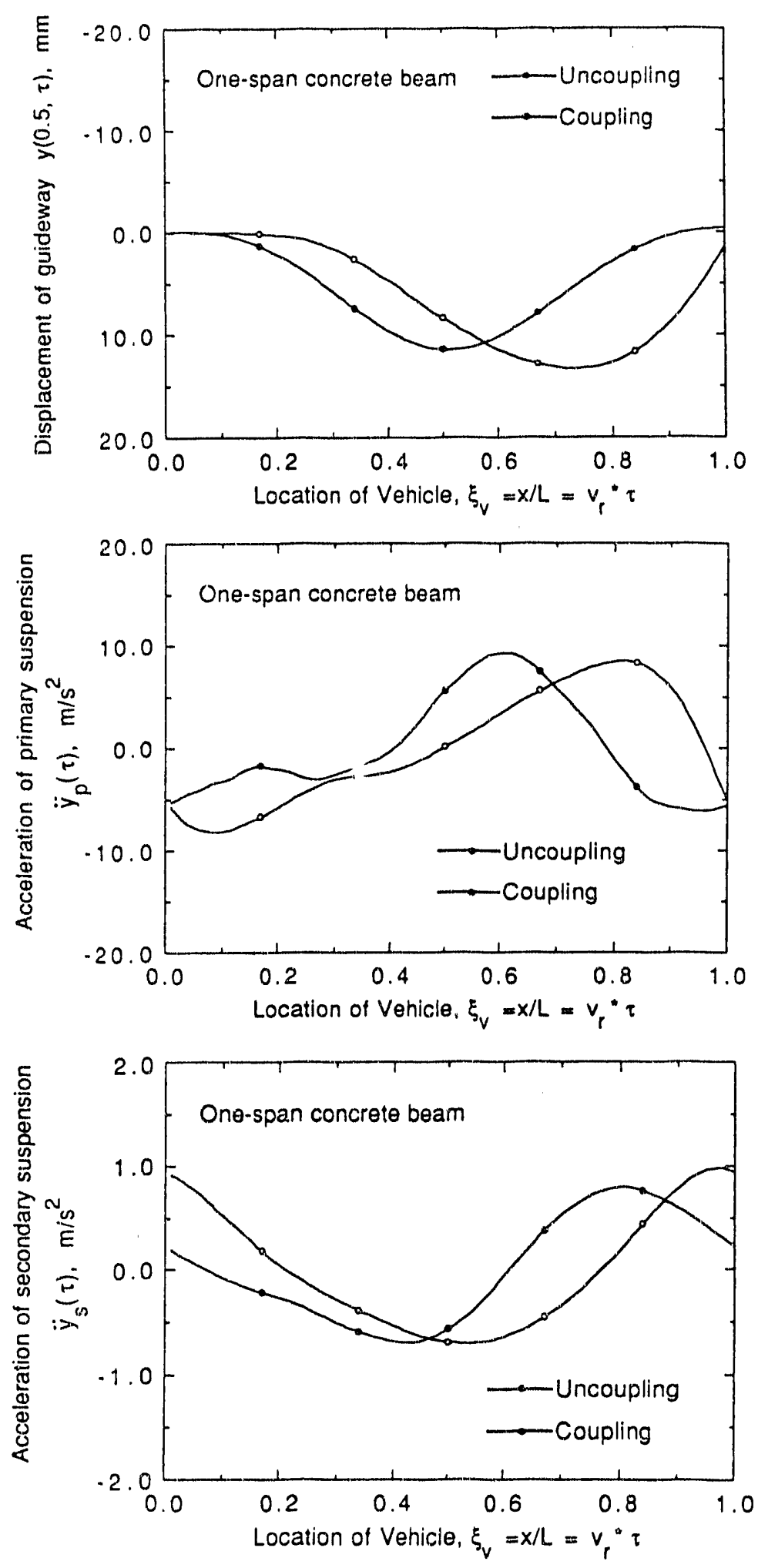

Fig. 24. Time histories of steady-state guideway displacement and vehicle acceleration of Transrapid with speed $v=400 \mathrm{~km} / \mathrm{h}$ on a singlespan concrete beam 

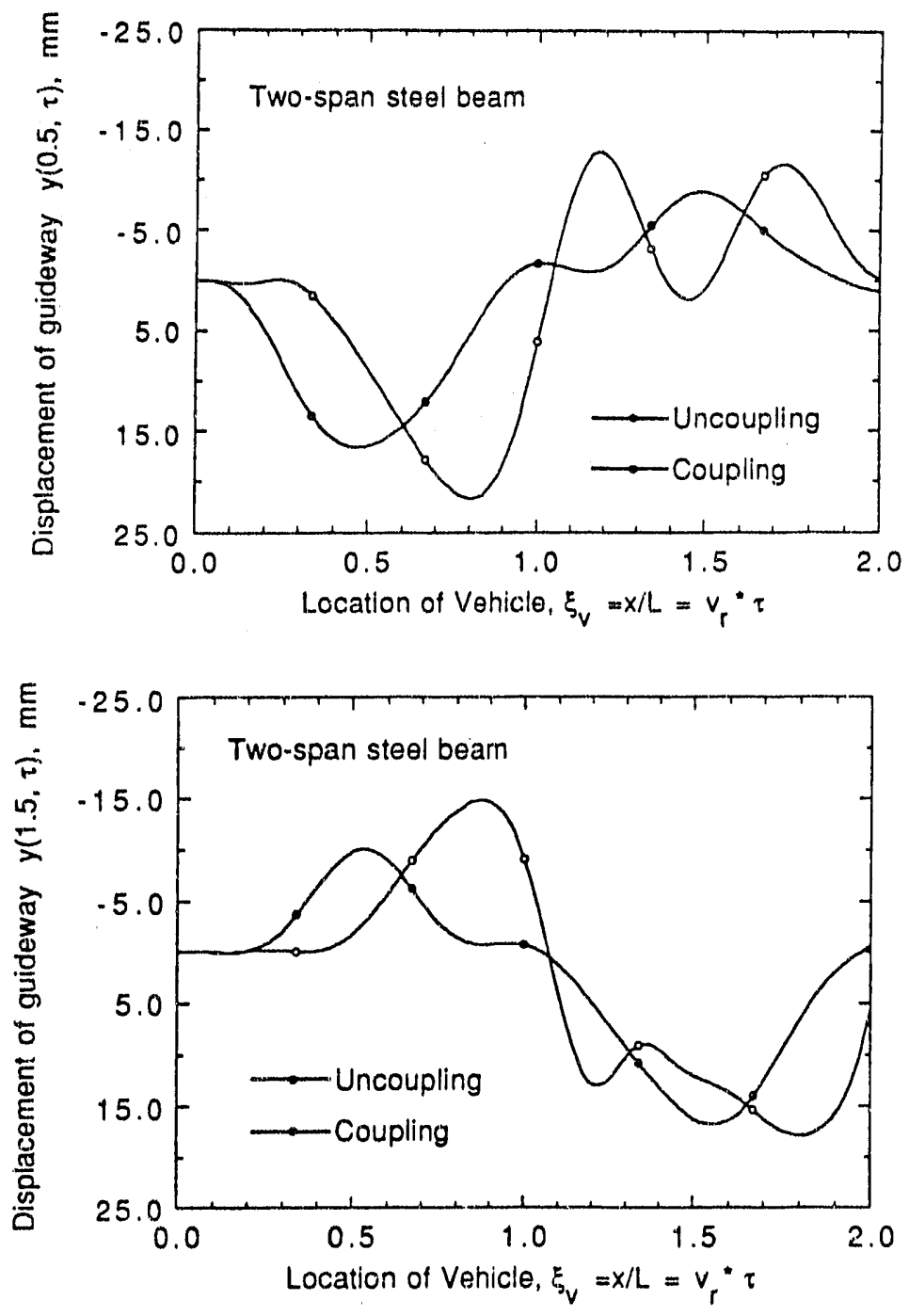

Fig. 25. Time histories of steady-state guideway displacement and vehicle acceleration of Transrapid with speed $v=400 \mathrm{~km} / \mathrm{h}$ on a doublespan steel beam 

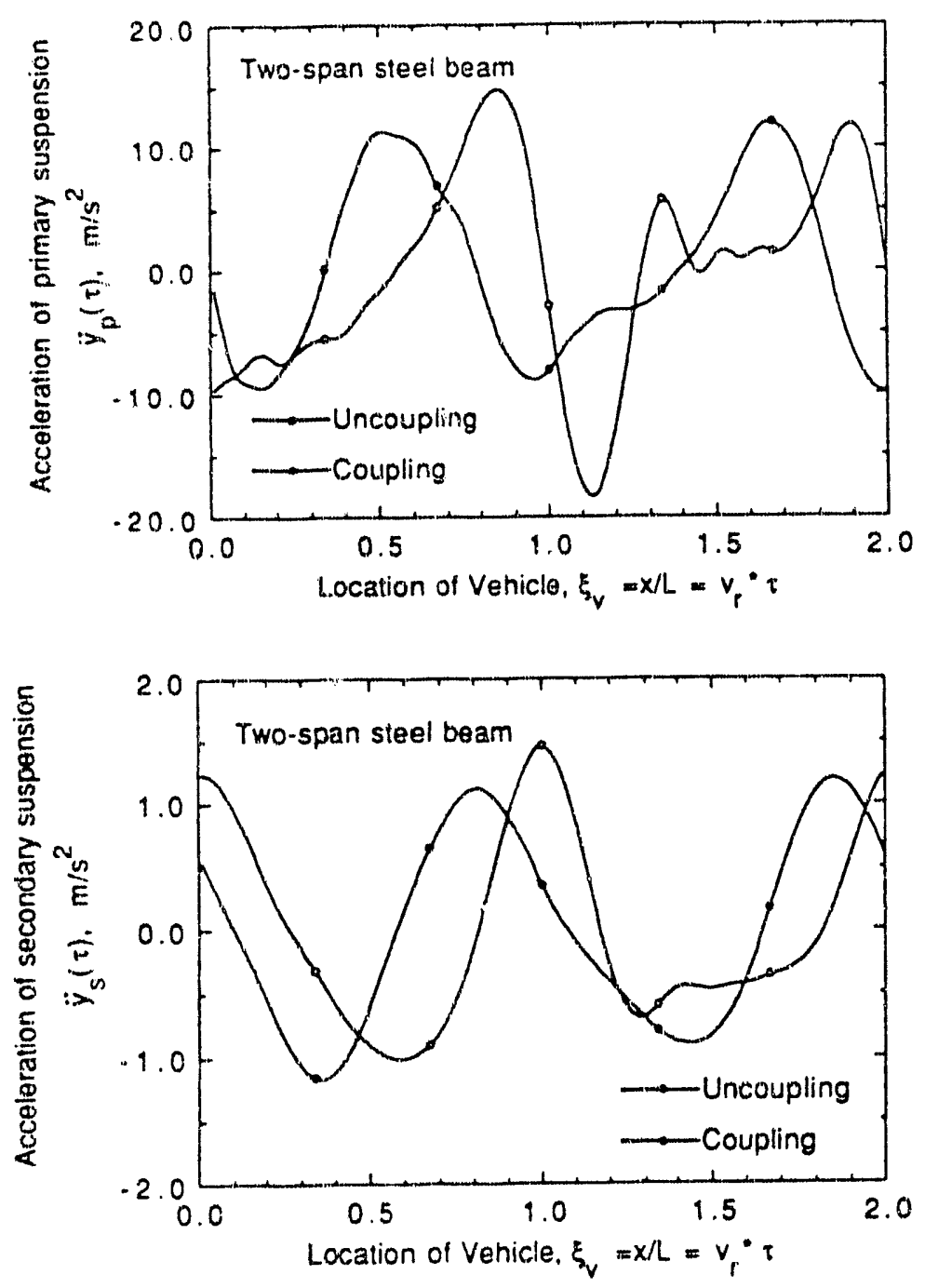

Fig. 25. (Cont'd) 
force on the beam when the maximum deflection occurs are functions of traveling speed. Within a certain range of traveling speeds (in practical applications of maglev, $v / v_{c}$ is most likely to be $<0.5$, where $v_{c}$ is the critical speed), the moving force will amplify beam displacement, so the maximum deflection of the beam with a moving force will always be larger than the static deflection due to a constant force at the midspan. Damping iends to decrease beam response regardless of the traveling speed of the moving force. In the case of a two-span beam, the maximum midspan deflection of the first span will be less than that of the single-span beam at any traveling speeds of the moving force; however, the maximum midspan deflection of the second span will be larger than that of the single-span beam when the traveling speed is $0.65-1.4 \mathrm{v}_{\mathrm{c}}$.

The vehicle model with two degrees of freedom consists of two masses, two springs, and two dampings, representing primary and secondary suspensions. The vehicle/guideway parameters, such as the ratio of traveling speed to critical speed, the ratio of vehicle to guideway mass and frequency, the ratio of secondary suspension to primary suspension mass and frequency, and vehicle and guideway dampings, are considered in the analysis of vehicle/guideway interactions within the range of practical interest. The influence of these parameters on the magnitude of guideway deflection and vehicle acceleration ratios were evaluated, and the results are compared with the situation when vehicle acceleration forces are neglected and only a constant force due to the vehicle weight is applied on the guideway.

The maximum guideway deflection that is directly related to the maximum stress and bending moment sustained by the guideway, and the maximum vehicle acceleration that is related to ride quality, are functions of traveling speed ratio and other vehicle/guideway parameters. A detailed study of those parameters indicates that when the vehicle traveling speed ratio is $<0.5$, and within some ranges of vehicle/guideway parameters (for example, the vehicle/guideway mass ratio $\varepsilon \leq 0.25$, the vehicle mass ratio $\gamma_{m} \leq 0.1$, and the vehicle/guideway frequency ratio $\Omega>3$ ), dynamic interaction between vehicle and guideway can be neglected. In this situation, dynamic motion can be decoupled, and furthermore, the vehicle model can be replaced by a concentrated moving force traveling on the guideway. For practical maglev systems, the vehicle traveling speed ratio is most likely to be <0.5. Therefore, the model of a moving force may be introduced into the dynamic analysis of maglev systems. In this range, the maximum displacement ratio of a two-span guideway is smaller than that of a single-span guideway. Without considering other factors, a two-span guideway appears to be more efficient in achieving better ride quality. 
For vehicle design, it is wise to increase the vehicle/ guideway frequency ratio $\Omega$, increase vehicle primary suspension damping $\zeta_{p}$, and decrease the secondary to primary suspension frequency ratio $\gamma_{\mathrm{f}}$ to obtain better ride quality.

Finally, the vehicle/guideway interaction of the German Transrapid system has been evaluated. From data in the literature, we find that guideway displacement and vehicle acceleration in that system exceed desired values without considering the feedback controller in the system. It is necessary to utilize the dynamic models to analyze the vehicle/guideway interaction of some maglev systems such as the German Transrapid system.

\section{Acknowledgments}

This work was performed under the sponsorship of the U.S. Army Corps of Engineers and the Federal Railroad Administration through interagency agreements with the U.S. Department of Energy.

\section{References}

Bohn, G., and Steinmetz, G. 1985. "The Electromagnetic Suspension System of the Magnetic Train 'Transrapid'," Proc. Int. Conf. on Maglev Transport '85, pp. 57-71. Published by the IEEE of Japan.

Chiu, W. S. et al. 1971. "Influence of Vehicle and Distributed Guideway Parameters on High Speed Vehicle-Guideway Dynamic Interaction," ASME Trans., J. Dynamic Systems, Measurement, and Control, pp. 25-34.

Coffey, H. T., Chilton, F., and Hoppie, L. O. 1972. "The Feasibility of Magnetically Levitating High Speed Ground Vehicles," Stanford Research Institute, Report No. FRA-PB210505.

Coffey, H. T., Colton, J. D., and Mahrer, K. D. 1973. "Study of Magnetically Levitated Vehicle," Stanford Research Institute, Report No. FRA-RT-73-24, PB221696.

Coffey, H. T., Colton, J. D., Solinsky, J. C., and Woodbury, J. R. 1974. "An Evaluation of the Dynamics of Magnetically Levitated Vehicle," Stanford Research Institute, Report No. FRA-ORD and D-74-41, PB236671/4GA.

Fryba, L. 1972. "Vibration of Solids and Structures Under Moving Loads," Noordhoff International Publishing, Groningen, The Netherlands. 
He, J. L., Rote, D. M., and Coffey, H. T. 1992. Argonne National Laboratory, unpublished information.

Iguchi, M., and Hara, H. 1985. "A Resonance-Eliminated Design of Simply Supported Beam for a Guideway of a High Speed Maglev System," Proc. Int. Conf. on Maglev Transport '85, pp. 217-224. Published by the IEEE of Japan.

Johnson, L. R. et al. 1989. "Maglev Vehicles and Superconductor Technology: Integration of High-Speed Ground Transportation into the Air Travel System," Argonne National Laboratory Report ANL/CNSV-67.

Katz, R. M. et al. 1974. "Performance of Magnetic Suspensions for High Speed Vehicles Operating Over Flexible Guideways," ASME Trans., J. Dynamic Systems, Measurement, and Control, Vol. 96, pp. 204-212.

Kerr, A. D. 1981. "Continuously Supported Beams and Plates Subjected to Moving Loads - A Survey," SM Archives, Vol. 6, Issue 4, pp. 401-449.

Philco-Ford Corp. 1975. "Conceptual Design and Analysis of the Tracked Magnetically Levitated Vehicle Technology Program, Repulsion Scheme. Vol. I., Technical Studies," Report DOT-FT-40024 (Task 1).

Richardson, H. H., and Wormley, D. N. 1974. "Transportation Vehicle/BeamElevated Guideway Dynamic Interactions: A State-of-the-Art Review," ASME Trans., J. Dynamic Systems, Measurement, and Control, Vol. 96, pp. 169-179.

Sinha, P. K. 1987. "Electromagnetic Suspension, Dynamics and Control." Peter Peregrinus Ltd., London, U.K.

Ting, E. C., Genin, J., and Ginsberg, J. H. 1974. "A General Algorithm for Moving Mass Problems," J. Sound Vib., Vol. 33, pp. 49-58.

Uher, R. A. 1989. "MAGLEV: An Emerging Transportation Technology to Meet an Imminent Transportation Need." Proc. Int. Conf. Maglev '89, July 1989, pp. 115-122.

Wilson, J. F. 1973. "Response of Simple Spans to Moving Mass Loads," AIAA J., Vol. 11, pp. 4-5.

Yadav, D., and Upadhyay, H. C. 1991. "Non-Stationary Dynamics of Train and Flexible 'Track Over Inertial Foundation During Variable Velocity Runs," J. Sound Vib., Vol. 147, No. 1, pp. 57-71.

Zicha, J. H. 1986. "Civil Aspects of Maglev Design." Int. Conf. Maglev and Linear Drives, Publication IEEE 86CH2276, pp. 69-87. 
Distribution for ANL-92/19

Internal

Y. Cai (10)

S. S. Chen (5)

J. $\mathrm{He}$

L. R. Johnson

C. A. Malefyt (2)

T. M. Mulcahy

D. M. Rote (10)

C. E. Till
R. A. Valentin

M. W. Wambsganss

Z. Wang

R. W. Weeks

ANL Patent Dept.

ANL Contract File

TIS Files (3)

\section{External}

DOE-OSTI for distribution per UC-330 (91)

ANL-TIS Libraries (2)

Manager, Chicago Operations Office, DOE

Direc ${ }^{\dagger}$ r, Technology Management Div., DOE-CH

D. L. Bray, DOE-CH

A. L. Taboas, DOE-CH

Materials and Components Technology Division Review Committee:

H. Berger, Industrial Quality, Inc., Gaithersburg, MD

H. Birnbaum, University of Illinois at Urbana-Champaign, Urbana

R. Buchanan, University of Illinois at Urbana-Champaign, Urbana

M. S. Dresselhaus, Massachusetts Institute of Technology, Cambridge, MA

R. A. Greenkorn, Purdue University, West Lafayette, IN

B. Jones, University of Illinois at Urbana-Champaign, Urbana

C.-Y. Li, Cornell University, Ithaca, NY

R. E. Smith, Electric Power Research Institute, NDE Ctr., Charlotte, NC 

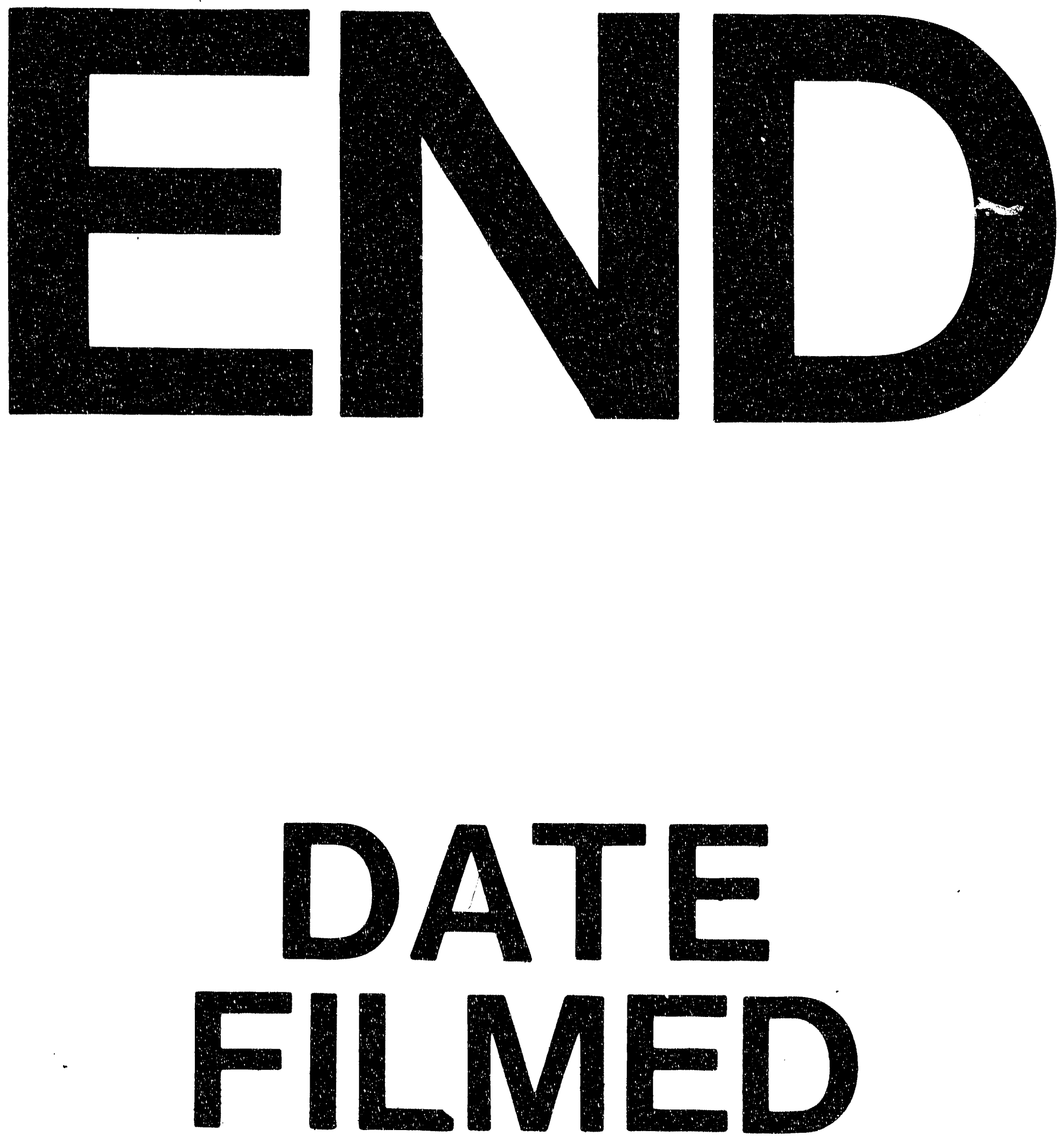

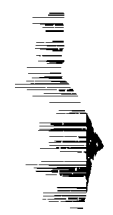

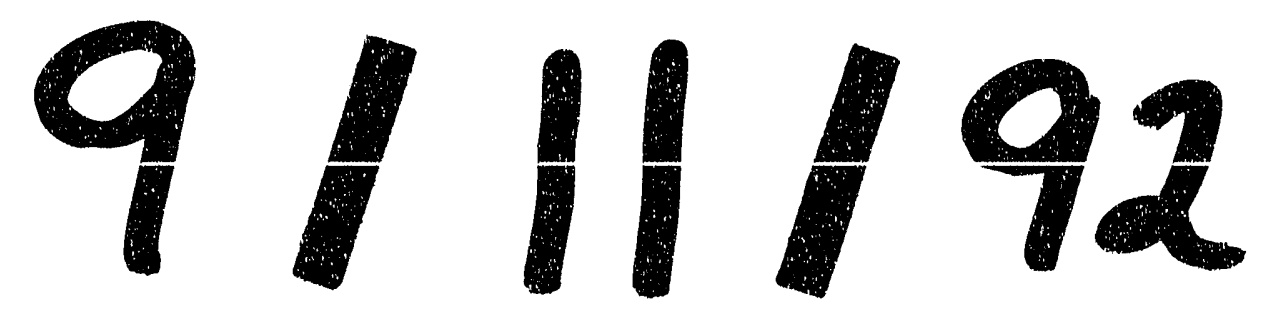




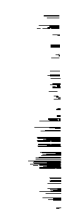

